\title{
EL COMPÁS Y LA PLOMADA: POÉTICA ESPACIAL Y METÁFORA LITERARIA EN DERECHO Y ARQUITECTURA'
}

\author{
José CALVo GonzÁLEZ²
}

\begin{abstract}
RESUMEN: El texto organiza las relaciones entre Derecho y Arquitectura en dos vertientes: indagando sobre lo jurídico en lo arquitectónico, y analizando lo arquitectónico en lo jurídico. Para la primera de ellas recupera antecedentes históricos de la evolución que conducirá a la actual configuración de los edificios judiciales, subrayando un proceso de transformación que va desde la existencia de construcciones multiuso (Basilicae romanas, Taverns inglesas, Townhouses estadounidenses y suecas) a una funcionalidad específica y exclusiva (Courthouses. Palais de Justice). El punto de inflexión se localiza en el aumento de la importancia económica de los procesos, la solemnidad del rito procesal y el creciente auge del prestigio profesional del abogado. El texto subraya también la innovación arquitectónica de los Tribunales apoyada, como soporte, en una arquitectura del castigo. Los nuevos edificios judiciales se cimientan sobre antiguas prisiones. Se ofrecen sugestivas referencias literarias y de historia del arte. Se examinan asimismo la disposición del ornato y la decoración de los interiores en relación a garantías procesales, derecho de defensa y publicidad. La segunda trayectoria presenta las metáforas arquitectónicas utilizadas en la filosofía jurídica estatal, la teoría del derecho, el derecho constitucional y la teoría de la argumentación.
\end{abstract}

Palabras Clave: derecho y humanidades; derecho y literatura; arquitectura; artificio.

\footnotetext{
1 Texto base de la conexión skipe de 29 de mayo de 2012 en videoconferencia organizada por el Professor Doutor Marcílio Toscano Franca Filho para los alumnos de la disciplina Metodología da Pesquisa en el Programa de Pós-Graduação em Direito (Mest./Dout.) do Centro de Ciências Jurídicas da Universidade Federal da Paraíba (Brasil).

2 Doctor en Derecho (Málaga/España). Catedrático de Teoría y Filosofía del Derecho de la Universidad de Málaga. E-mail: jcalvo@uma.es
} 


\section{SOBRE ARQUITECTURA JURÍDICA:}

\section{LO JURÍDICO EN LO ARQUITECTÓNICO}

Parece sensato que en una breve disertación como ésta respetemos el principio arquitectónico de no comenzar la casa por el tejado. Por tanto, habré de iniciar su construcción por la base. Y así, habrá que decir, en el principio no había edificaciones. Por entonces sólo había selva.

En los pueblos primitivos, que vivían entre los bosques, la arquitectura era muy elemental y poco consistente. Aquella humanidad hacía poco que dejó de ser nómada, y cuando comenzó a tomar conciencia de la necesidad de dirimir de un modo pacífico sus conflictos - que aunque en su mayoría ya eran jurídicos no todavía serían siempre judiciales, o sólo potencialmente - acudía a un claro de bosque, o al centro de la aldea en que se había asentado la tribu, y allí o aquí, bajo las ramas protectoras de un árbol sagrado, reunido el consejo de los mayores, de los ancianos, deliberaban y resolvían. Aquel árbol, producido por la naturaleza y al que se otorgaban poderes mágicos, fue el primer cobijo del Derecho. Un derecho probablemente tan natural como el mismo árbol. En mitad de la naturaleza surgió el Derecho, y si de alguna arquitectura cupiera hablar para aquellos espacios abiertos en el corazón del frondoso arbolado sería por tanto de un cierto paisajismo, de una incipiente arquitectura del paisaje.

Con el tiempo aquellas tribus aumentaron de tamaño y fueron pueblos y arraigaron más profundamente en su primitivo hábitat, y algo después aparecieron los poblados y pronto las primeras ciudades. Las polis de la antigua Grecia también situaron en un lugar central el acto jurídicamente relevante de juzgar. Fue en el ágora. De ese modo, en lugar tan destacado como el centro de sus emplazamientos habitacionales, la zona más pública e idónea para las grandes reuniones, juzgaban y resolvían sus pleitos. La justicia se administraba en abierto, en público. La justicia se impartía a cielo abierto, en las plazas, y en público, a la vista de todos.

De la continuidad de un asentamiento puramente físico pasaremos con el tiempo a la consciente y afirmada fundación de urbes; Ad condita urbs. El acto fundacional del establecimiento de un núcleo urbano vincula elementos arquitectónicos y jurídicos, une Derecho y Arquitectura. Roma se construyó en la excavación de un foso, el mundus, luego cubierto por una losa de piedra cuadrada, Roma quadrata, y desde el trazo circular de su 
perímetro, el pomerium. En el mundus se introdujeron las primicias de todas las cosas que son tenidas como buenas por ley y necesarias por naturaleza. El pomerium, frontera sagrada, se fortificó con murallas, res santae, Res extra comercium divini iuris. Sobre el mundus emergería el Forum, y en él fueron erigidos templos y altares, cosas con igual condición sacro-jurídica, y aparecieron asimismo las Res extra comercium humanis iuris, tales que las res publicae, y otras como las Res comunes omnium, cuyo uso el pueblo de Roma reservaba a todos los ciudadanos, y también las Res universitatis, que eran comunes a todos ellos.

Pero cuando el mundus de Roma devino en centro del Universo y atrajo a multitud de hombres y mujeres de todas partes de Italia y aún de muy lejanos confines más allá de aquella península, cuando su población creció exponencialmente, ya siendo Roma la capital del Imperio, la ciudad eterna se convirtió en un verdadero desbarajuste. Resultó necesario, por tanto, intervenir jurídicamente y adoptar algunas disposiciones sobre la espontánea y desquiciante ocupación del dominio público en la ciudad de Roma, ya que tal práctica había alcanzado niveles de auténtico problema "de estado", y también muy graves para la calidad de vida de todos los romanos sin distingo de clase o posición.

En un pasaje de Yo Claudio, la novela de Robert Graves, se aprecian las dificultades de Augusto (27 a.C-14 d.C) para conciliar el sueño. No era que padeciera insomnio, sino que pasaba las noches en vela a causa del ruido. Adriano había prohibido la entrada de carros a la ciudad, de modo que era en horas nocturnas cuando Roma se avituallaba de todo género de materias alimentarias y de cualquier otra naturaleza, y el ruido de los carruajes y las invectivas de las gentes de esos transportes, el lenguaje soez de los carreteros, impedía dormir. Roma era de día y de noche un inmenso mercado instalado en el corazón de una bella ciudad salpicada en todas partes de templos, edificios públicos, palacios, columnas, estatuas y arcos triunfales con que Augusto embelleció su arquitectura (ideo legibus Urbem fundavi/ operibus ornavi)3. Pero no fue hasta tiempos de la dinastía flavia, con Tito Flavio Domiciano, emperador del 81 al 96, que se trató de ordenar

3 De su obra dice el propio Augusto: "ldeo civilia bella compescui, /ideo legibus Urbem fundavi/ operibus ornavi ut ...", Apoc. 10,2. ("Hasta tal punto reprimí la contienda civil [y] legislé para la ciudad [y] la adorné en su arquitectura que...”). 
el espacio urbano de Roma. Uno de los epigramas de Marcial describe la situación previa al remedio de las nuevas ordenanzas:

Se había apoderado de la ciudad el tendero temerario y ningún dintel se mantuvo en sus propios límites Has ordenado Germánico que crecieran los barrios y lo que antes fue una senda se convirtió en avenida. No hay ninguna pilastra rodeada de redomas [encadenadas ni se obliga al pretor a ir por el barro, ni una navaja se saca ciegamente en medio de un gran [gentío, ni negra cantina ocupa toda la calle Barbero, tabernero, cocinero, carnicero, respetan su [propio umbral ahora es Roma, antes era una gran taberna4

Nunc Roma est, nuper magna taberna fuit; Roma tabernaria y de las mil popinae (cantinas). El epigrama de Marcial se refiere a las limitaciones en la ocupación ilícita del dominio público por parte de los institores introducidas por un decreto de Domiciano del año 92 d.C5. Con ésta y otras medidas, logró el praetor, en efecto, no caminar sobre el barro, y llegar en buenas condiciones de higiene e integridad física hasta la Basílica, que era el lugar en que ejercía su magistratura. Al pretor le había sucedido lo que al edificio que albergaba el officio de su imperium: la iurisdictio (dicere, dare, iudicium dara, iudicare iubere) El pretor tiene origen militar, esto es, el que va al frente de las tropas, prae ire, y con el tiempo y las nuevas circunstancias políticas asumió tareas jurisdiccionales. La Basílica fue siempre un edificio público de versátil funcionalidad: en principio destinado al culto, pero también mercado y lugar de transacciones financieras, además de sede de la administración de justicia ${ }^{6}$. Que la Justicia se conjuntara en aquel edificio a la religión, el mercadeo y los negocios, parece algo significativo. El pretor, escoltado por sus lictores,

4 Abstulerat totam temerarius institor urbem, /Inque suo nullum limine limen erat./Iussisti tenuis, Germanice, crescere uicos,/et modo quae fuerat semita, facta uia est./Nulla catenatis pila est praecincta lagonis,/nec praetor medio cogitur ire luto,/stringitur in densa nec caeca novacula turba,/occupat aut totas nigra popina uias./Tonsor, copo, cocus, lanius sua limina seruant./Nunc Roma est, nuper magna taberna fuit. (Mart. 7,61 .)

5 La regulación completa de estas edificaciones se producirá con la Constitución de Zenón de aedificiis privatis, promulgada hacia el 474 d.C. y que se halla recogida Libro Octavo del Código de Justiniano. Vid. C.8,10,12,6. Asimismo, Belén Malavé Osuna (2000).

6 Sobre la inexistencia en Roma antigua de edificios exclusivamente reservados a la administración de justicia vid. Erik Kondratieft (2010, p. 87-126). 
ocupaba en todo caso la zona más destacada de la gran sala rectangular con que se formaba su planta, situándose en la nave principal, donde instalaba el emblema de su imperium y sobre estrado la sella curulis, en la que desde tomar asiento concedía a los litigantes, de los que se hallaba separado por cancili, la actio que presentar al iudex privatus elegido por las partes en el album iudicis, hecho público cada año y expuesto en una de las columnas del Foro. Con el tiempo y la mayor complejidad de los asuntos el pretor se asesorará de consejeros, su consilium, y de esclavos que actuaron como auxiliares del tribunal.

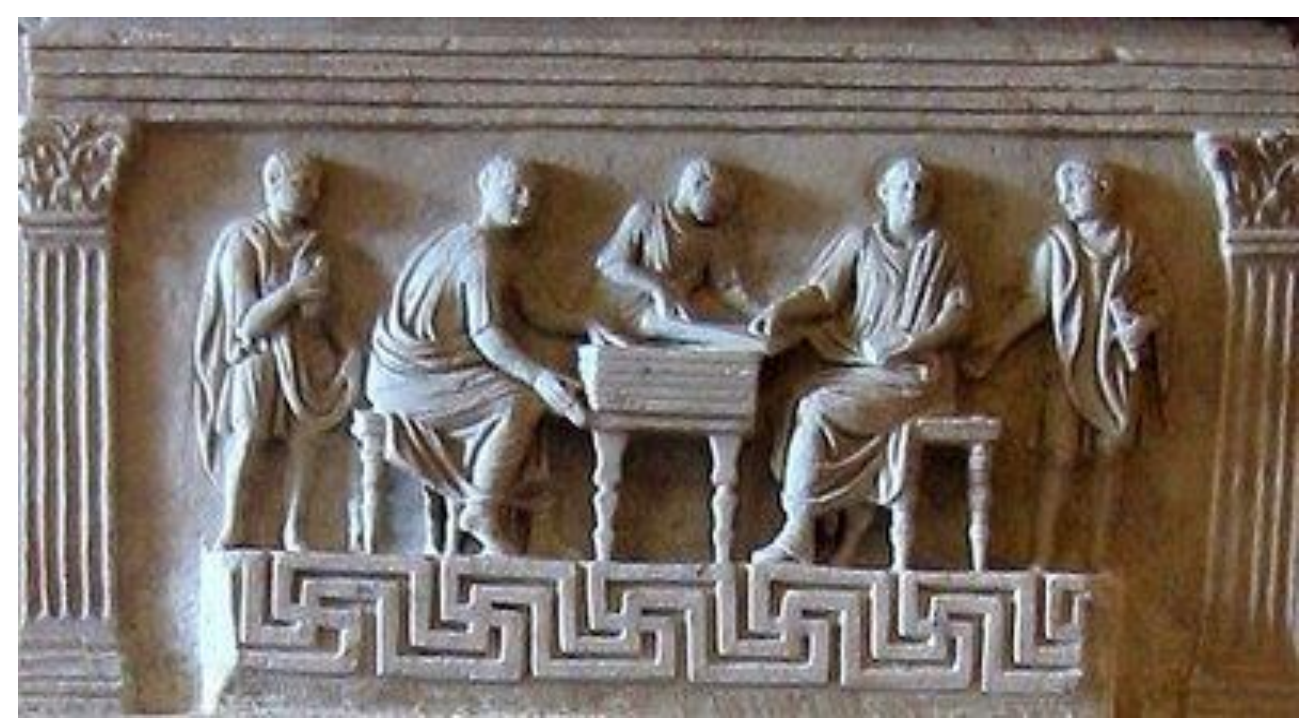

Claro es que a lo largo de los años -de los siglos, mejor- el proceso romano (en su bipartición de fases in iure e in iudicium) modificó parte de sus ceremonias y ritos procedimentales (legis acciones, per formulas y extra ordinem $)^{7}$, pero en general esto que he dicho sirve aquí para concretar que en esta estadía de la historia jurídica romana la administración de justicia no se lleva a tan a la vista del público, sino en un lugar cerrado y cubierto, ciertamente. Pero asimismo en un emplazamiento señero e identificable, como era el edificio de la Basílica Amilia, lo que añadía la ventaja de ser perfectamente localizable. Esta circunstancia arquitectónica es importante. Los ciudadanos sabían con facilidad dónde

\footnotetext{
7 Legis acciones: desde los inicios de Roma hasta mediados del s. II a.C.; Per formulas, de mediados s. II a.C. al s. III; y Extra ordinem hasta final del Imperio, si bien coexistiendo con el formulario.
} 
dirigirse y cómo orientarse cuando precisaban resolver sus conflictos de Derecho. El Tribunal Praetoris era un notable edificio ubicado en el Foro, con las Tabernae novae adosadas a su muro oeste, y tenía como referencias de situación más indicativas la escultura del frigio Marsias, erigida desde el año 8 a.C., cerca de la higuera Ruminal, el Lacus Curtius o la Curia Julia.
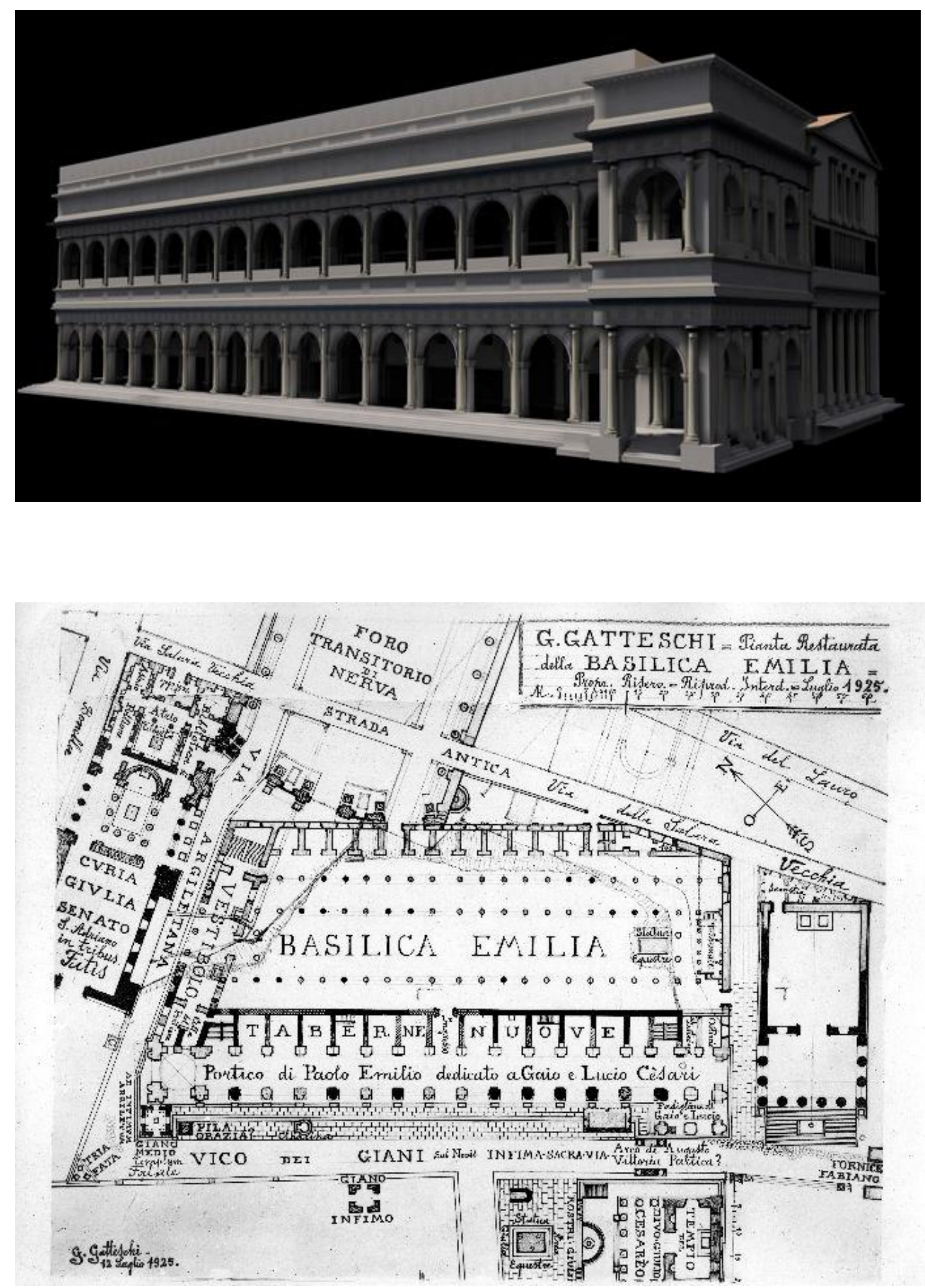


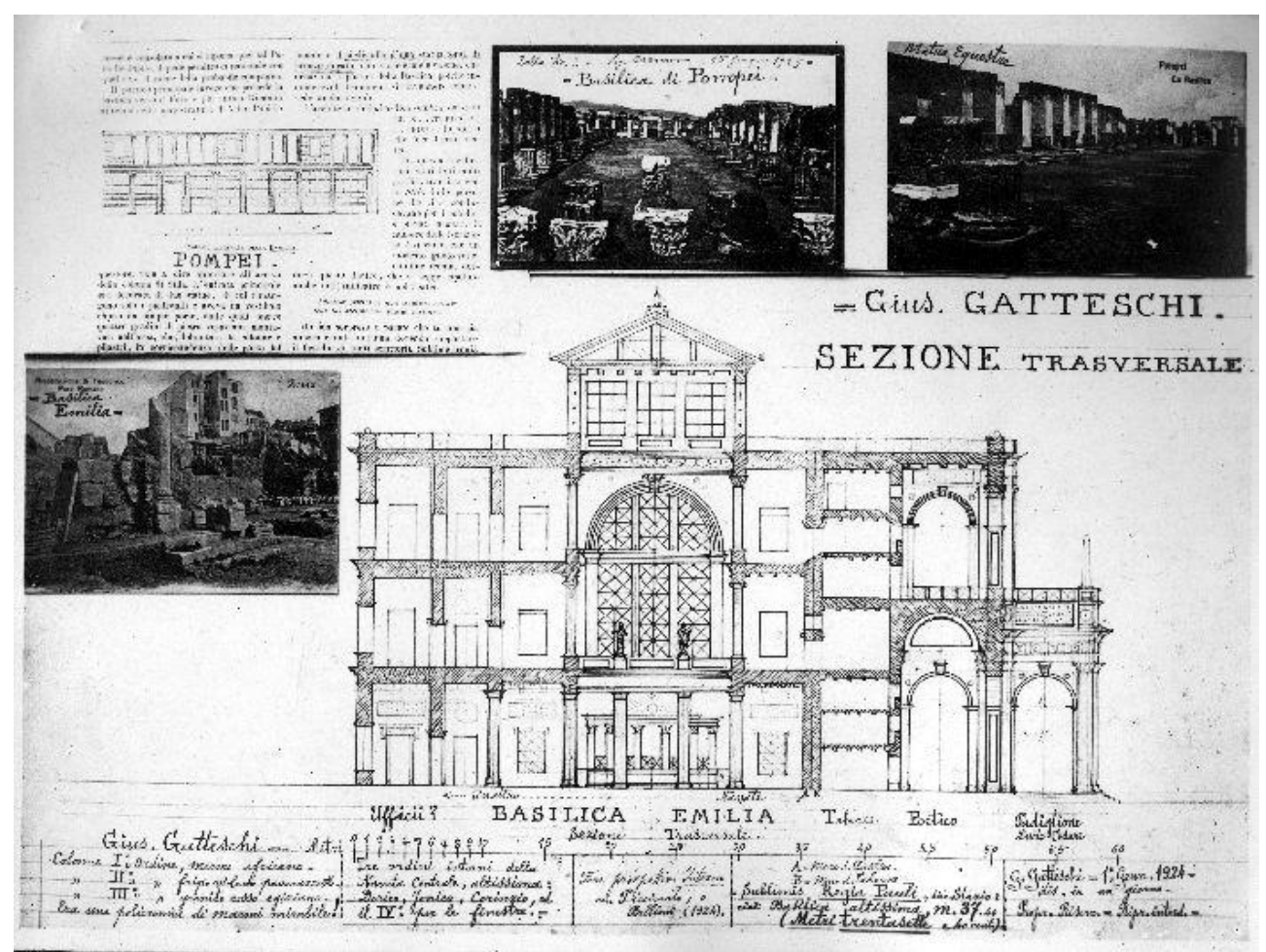

Basílica Emilia. Planimetria ricostruttiva, luglio 1925. Col. Giuseppe Gatteschi, Architettura e disegni ricostruttivi di Roma imperiale. Archive of the American Academy in Rome

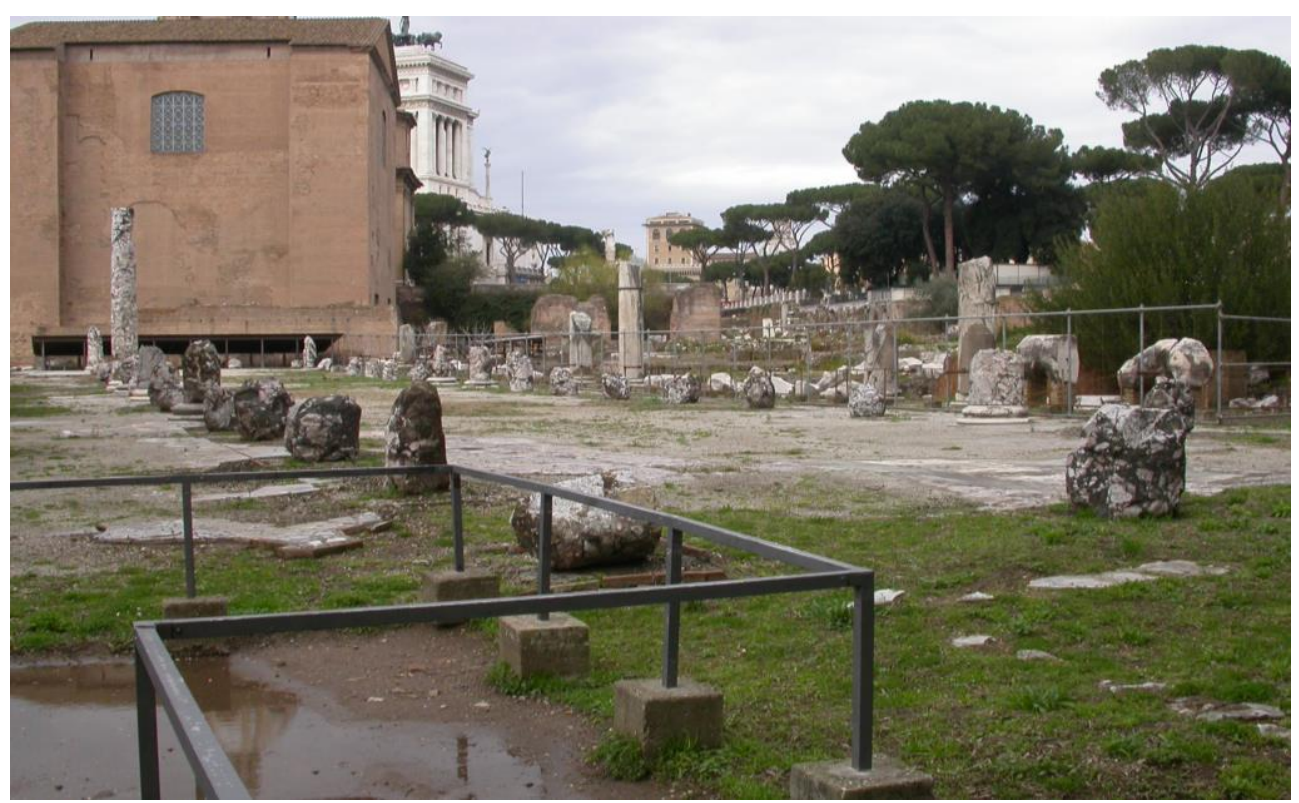




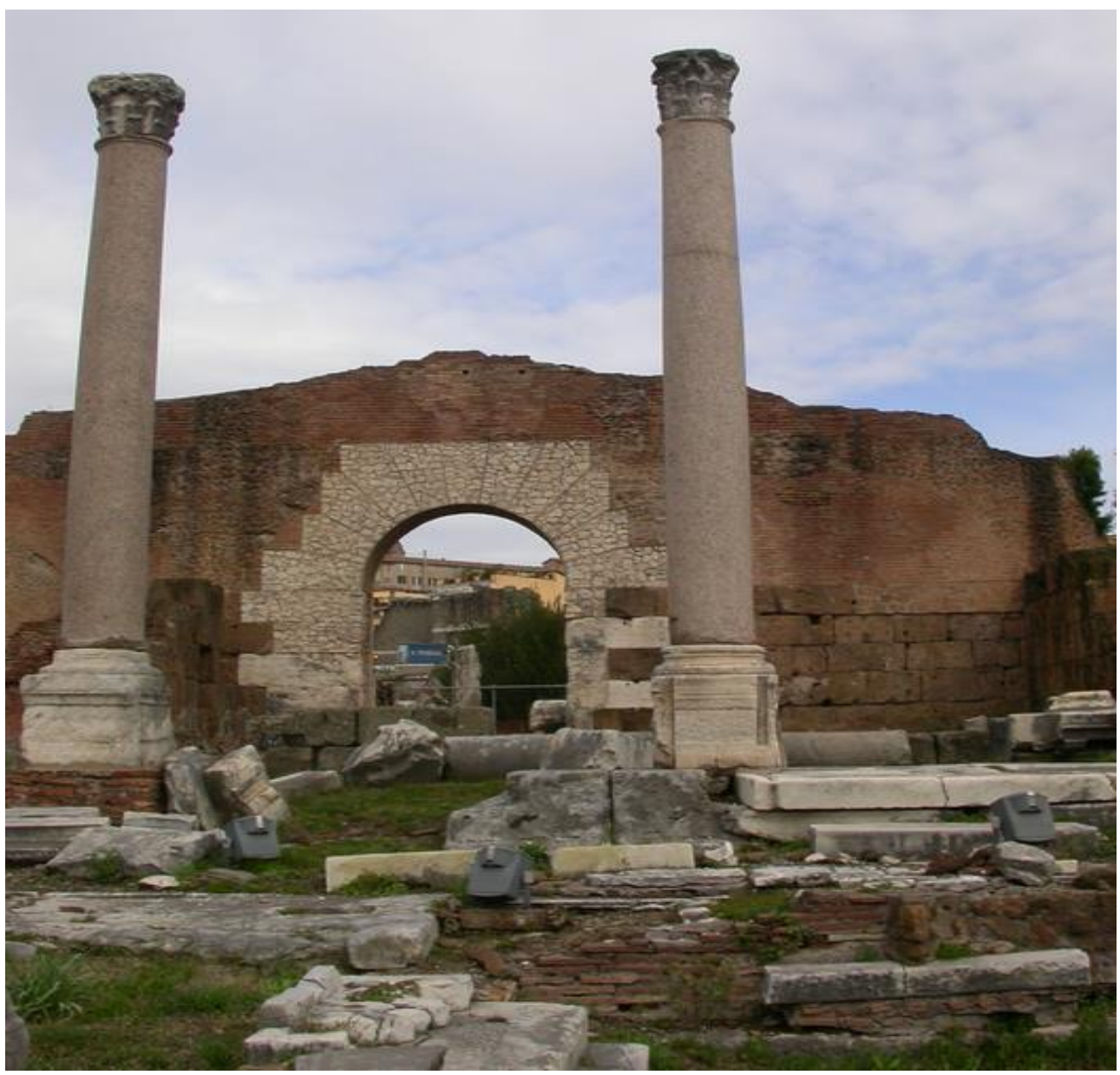

Restos de la Basílica Emilia

No obstante, conviene señalarlo, con la figura del praetor urbanus y la basílica convivió otro magistrado que, por la condición ambulante de su officium iudicis, lógicamente no dispuso de sede estable; esto es, el praetor inter cives et peregrinus. Éste continuó en el polvo y el barro de caminos secundarios y veredas -que no siempre ni a todas partes llegaron las famosas vías y calzadas romanas- y los recorría en su carreta, que portaba la emblamata y la selle, y administraba justicia al aire libre y entre los árboles.

Sucedería esto mismo en otros lugares del mundo, y aún hoy; son los tribunales ambulantes que visitan pequeñas y aisladas poblaciones rurales para impartir justicia. Valga recordar el film El último viaje del juez Feng ${ }^{8}$,

8 Título V.O. Mabei shang de fating (2006), dirigida por Jie Lui. 
$\mathrm{y}$ aquel veterano y prudente juez transitando angostos senderos de la provincia china de Yunnan, a menudo aplicando derecho consuetudinario, el derecho de la tierra, seguido de su sucesor, un joven magistrado que no siempre comprende la realidad del vario y rico derecho de las comunidades campesinas frente a las demasiado uniformes leyes estatales, y al que su terquedad jurídico-formal pone en peligro de originar o atizar, antes que evitar o paliar, el mismo conflicto sobre el que hubiera tenido que pronunciarse. Como la del pretor peregrino es ésta una justicia que se representa sin arquitecturas, o cuya sola arquitectura es la fortaleza del edificio de quien con sabia prudencia la imparte.

Dando ahora un gran salto llevo la palabra de esta charla hasta la Edad Media. Se trata de un período en todo momento difícil de reconstruir. Arriesgaré a decir -en absoluto me considero un especialista- que durante su arco temporal más oscuro, para aquellas jurisdicciones que funcionaron en un primer período y durante el intermedio, no existieron edificios destinados en concreto a la administración de Justicia, al menos edificios representativos de ello, por lo que debieron ser empleadas construcciones ya existentes, a las que se introducían modificaciones o reformas, nunca demasiado estructurales.

Fuera de ello, el carácter señorial de la justicia a lo largo del alto y medioevo invita a pensar en una justicia nobiliaria y real; los castillos, los palacios 9 , y hasta catedrales e iglesias acogieron las salas de justicia y tribunales. Y aún durante la Edad media tardía; de ella hallamos un simbólico ejemplo en el originario Palazzo del Comune de Verona (s. XII), construido sobre el antiguo foro, que primero será sede del Tribunal del Distrito y del Tribunal Penal, y más tarde -s. XIII- también de tribunales civiles, del Colegio Notarial y de la Cámara Fiscal, además de prisión, granero público y depósito de sal. Pero he hablado de 'simbólico ejemplo', de modelo casi, con una intención más profunda que ahora desvelaré; y es que en el año 1447, es decir, en pleno quattrocento, se le añade del lado de la actual Piazza Erbe un hermoso acceso escalonado de estilo tardogótico, en mármol rojo veronés, que es conocido como la Scala della Ragione y que

9 Como los que en España sirven de sede a la Real Chancillería de Valladolid en 1371, y Granada, 1505 . 
con el tiempo dará nombre a todo el conjunto, designándosele Palazzo della Ragione. iCuán hermoso imaginar que todos los edificios que albergasen órganos de la Administración de Justicia, y que en mi país comúnmente muchos aún se llaman Palacios de Justicia, fueran realmente Palacios de la Razón.
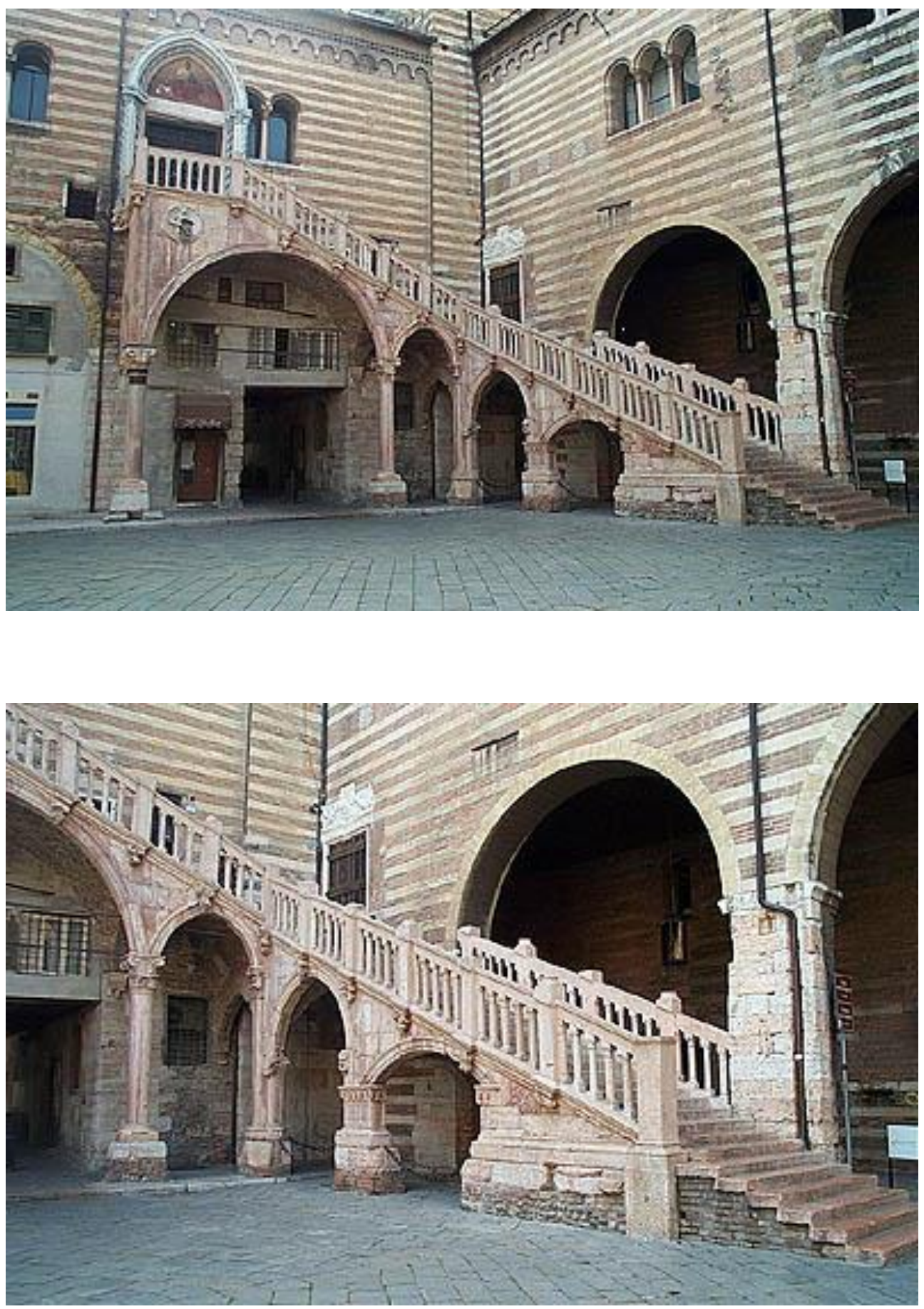

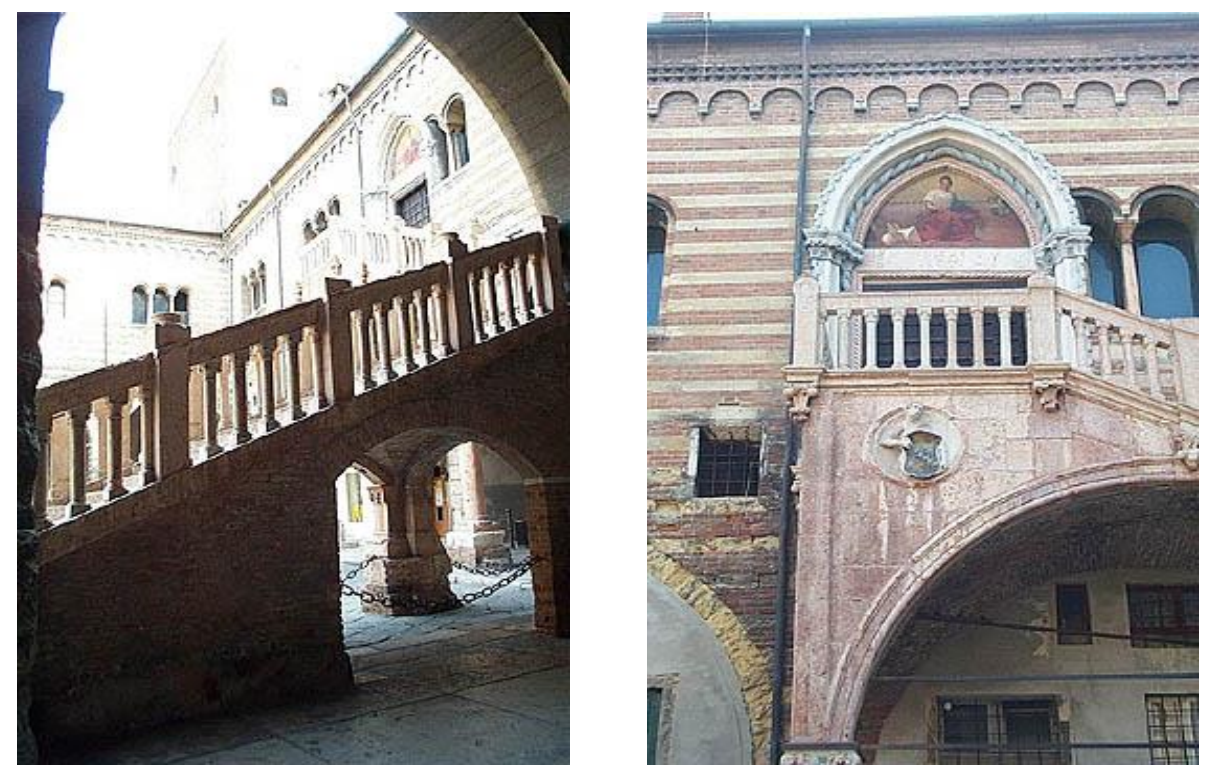

Con la llegada del Renacimiento y, sobre todo, conforme vayamos acercándonos al Barroco sucedería de otro modo. Creo que pueden existir dos motivos. Uno devendría, al menos en Italia, por influencia de los principios arquitectónicos contenidos en el tratado De Architectura de Vitruvio, de clásica mesura, e igualmente de artistas arquitectos como Palladio. De todo ello queda reflejo en la fábrica de edificios concebidos para instalar tribunales y salas de justicia y en la disposición espacial y estética de su interior. La idea allí reflejada se vincula a la metáfora escénica del theatrum veritatis et iustitia, con muestrario de imágenes de virtudes y corrupciones, y se encuentra unida asimismo a la rigurosa disciplina de las artes predicandi, en concreto a la rethorica, siendo que tanto lo constructivo como ornamental actúa para favorecer el desarrollo de facultades mnemotécnicas.

He tenido la fortuna de hallar una referencia que lo explica e ilustra. La ofrece Aldo Mazzacane, catedrático de Historia del Derecho de la Università degli Studi di Napoli 'Federico II', al escribir que, aun cuando de tales recursos se auxilian religiosos y predicadores, son sus destinatarios naturales "también los abogados":

Para ellos está preparada la imagen familiar de la sala de un tribunal, en la que están presentes el juez, las partes, los defensores, los testigos, el público, y también el espacio físico del recinto: las columnas, las divisiones de ambiente, la colocación de los asientos de los magistrados. Estas figuras pueden servirle al abogado para la fijación de nociones ordenadamente expuestas, para su más fácil memorización: a la figura del juez 
corresponderá la solutio que se querrá sostener en una quaestio dudosa cuyas tesis son dos, como las partes: a la sucesión de pilastras o columnas corresponderá la sucesión de los argumentos, etc. (Mazzacane, 1997, p. 75114).

Lo que de esta cita me interesa particularmente es el ad litteram relativo a que a la sucesión de pilastras o columnas corresponderá la sucesión de los argumentos; es decir, lo que aprovecha a una primera relación entre Arquitectura y Argumentación jurídica. De otras utilidades como la comparativa de instrumentos, elementos o parámetros arquitectónicos en la nueva retórica jurídica daré cuenta más adelante.

Ahora queda referir el segundo de los motivos anunciados. En mi opinión, los tribunales y salas de justicia irán adquiriendo identidad arquitectónica propia -material y funcional- bajo tres directrices: conforme la institución estatal más se afiance y crezca, de acuerdo a la progresiva importancia del interés económico de los contenciosos que ante los tribunales se deduzcan, y en consonancia a la elevación del status social de los profesionales del Derecho, en espacial del abogado.

Un ejemplo de ello lo tenemos en la evolución y transformación de los edificios y recintos destinados a la administración de justicia en Inglaterra y los Estados Unidos de América de Norte entre los s. XVII al XIX.

En este año que conmemoramos el bicentenario del nacimiento de Charles Dickens una de sus novelas puede resultar buena ocasión para introducirnos en ese proceso evolutivo. Se trata de Bleak House, publicada en 1853, y me interesa de modo especial una línea de su cap. XI, donde se relatan diversas diligencias practicadas en la indagatoria forense conocida como Coroner's Inquest, y aunque ciertamente no se la debe confundir con un juicio o Trial en sentido propio, nos será aquí de utilidad respecto al mejor conocimiento de las instalaciones judiciales en esa época. Veamos que dice el fragmento:

El Coroner se sentará en la habitación del primer piso en la taberna Sol's Arms, donde se celebran los Encuentros Armónicos dos veces a la semana [...] El Sol's Arms hace un gran negocio ese día. Incluso los niños necesitan, con tanta agitación, un refrigerio, así que un pastelero que ha situado provisionalmente su puesto en la esquina del patio dice que sus bombones de licor se venden como rosquillas. Entre tanto, el pertiguero, yendo y viniendo entre la puerta del establecimiento de Mr. Krook y la 
puerta de Sol's Arms, satisface la curiosidad de algunas personas discretas aceptando a cambio una cerveza.

Como se ve, el Coroner responsable de la indagatoria forense a la que presta su nombre, y cuyo proceder Dickens ${ }^{10}$ ya se había censurado, la realiza en un establecimiento público, en concreto una tavern, que es algo más parecido al negocio de un tendero romano que a un pub de nuestros días. Además, en mi entender, Dickens desliza una crítica aún más mordaz al blasonar aquel local con el icono solarl (Sol's Arms), lo que no sería sino una sutil e implícita alusión al grabado Sol Iustitiae (Sun of Justice) de Albrecht Dürer, fechado en 1498, y también conocido como El Juez o La Justicia.

Pero al margen de esta digresión, en la cita de Bleak House me importa en especial y antes que nada el segmento de la primera línea donde se lee El Coroner se sentará en la habitación del primer piso en la taberna Sol's Arms. Pues bien, un instructivo trabajo interdisciplinario como el llevado a cabo por Martha J. McNamara, profesora asociada de Historia en la Universidad de Maine, establece el tránsito a una identidad arquitectónico-judicial titulando expresivamente su investigación como From Tavern to Courthouse (McNamara , 2004). La tesis allí sostenida parte de identificar una primera etapa de la historia colonial norteamericana donde habrían actuado operadores judiciales sin experiencia y se utilizaban edificios destinados a otros fines, tales como tabernas o casas de reunión de congregaciones (taverns and Congregational meeting houses); es decir, edificios de usos múltiples (multipurpose buildings), o lo que es igual, con posibilidad de ofrecer multiservicio -de parecido sui generis a la basílica romana, si bien algo más mistificada y profana- y que eran conocidos como townhouses. Su modelo constructivo fue el de un edificio en dos niveles, esto es, planta baja y primer piso. La planta baja, situada a nivel de calle, reunía una o varias taverns o tiendas abiertas al público, mientras en el primer piso se localizaban una o varias habitaciones para usos gubernamentales y comunitarios.

${ }^{10}$ Vid. Charles Dickens (1850, p. 109-113) contrario a la práctica de estas diligencias precisamente en establecimientos públicos. 
Volvamos ahora al texto dickensiano releyendo la frase completa: $E l$ Coroner se sentará en la habitación del primer piso en la taberna Sol's Arms, donde se celebran los Encuentros Armónicos dos veces a la semana. Por consiguiente, la descripción del Sol's Arms se ajusta en todo a la de un Townhouse.
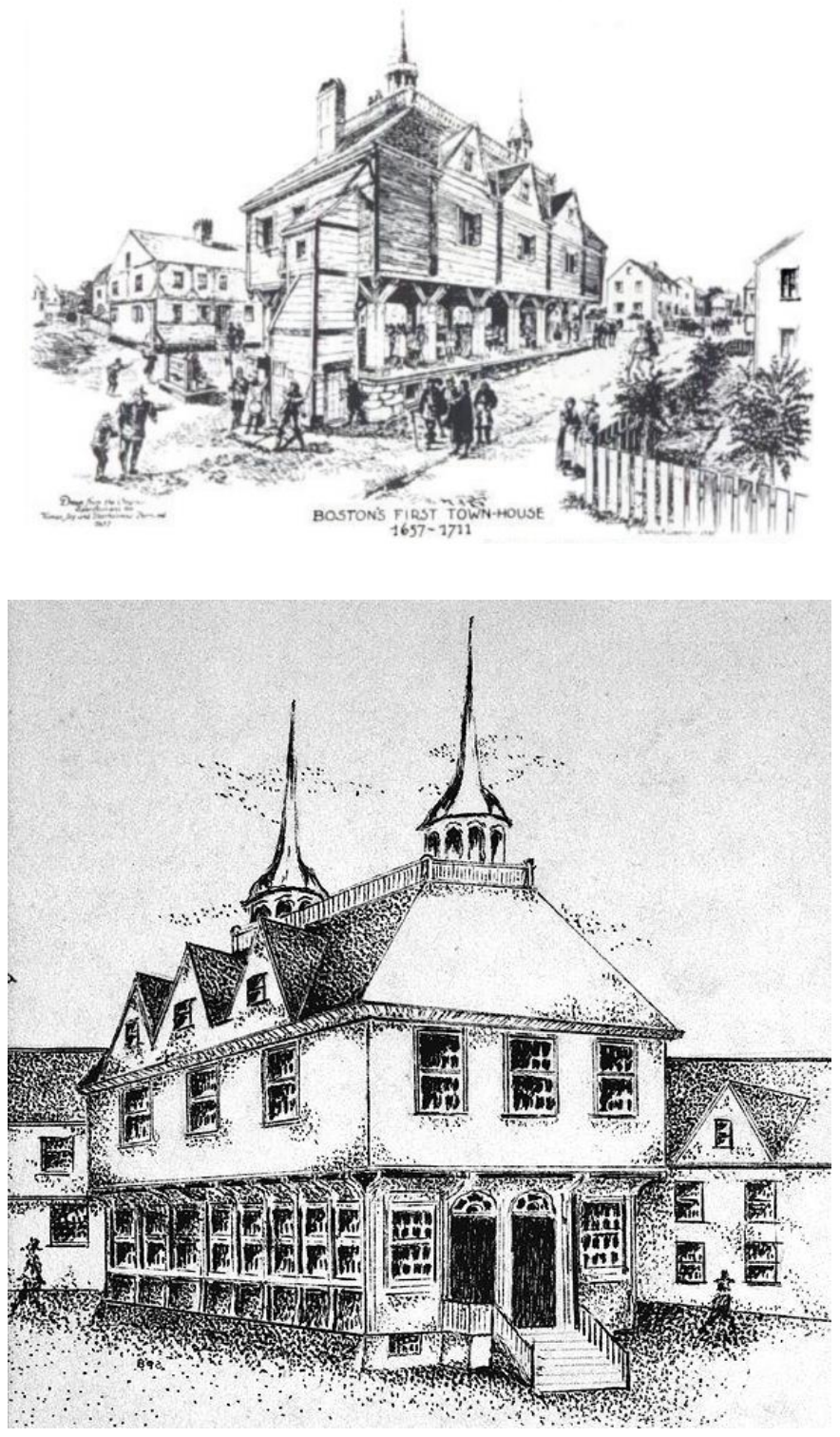

Es una pena que la interdisciplinaridad del método seguido por McNamara no haya acudido a fuentes literarias. Su trabajo, no obstante, se colma de interesantes hallazgos y acertadas conclusiones. Así, que en efecto 
aquella distribución no ofrecía suficiente división espacial, lo que tampoco contribuía a dotar de formalidad la imagen de la profesión jurídica ni a proyectar adecuadamente la solemnidad de sus ritos ${ }^{11}$.

En la etapa siguiente, y al objeto de intentar reforzar su peso social y respetabilidad profesional, las propias comunidades jurídicas elevarán el umbral de exigencias en formación y conocimiento técnico del Derecho que deban poseer jueces y abogados, cuidarán por establecer reglas para el trámite procesal, jerarquizarán funciones y tareas dentro de la oficina judicial y el tribunal, y financiarán proyectos arquitectónicos en los que el plano que sirva para construir el edificio público destinado a la gestión administrativa y de impartición de la Justicia ofrezca, desde su fachada hasta la distribución interior del espacio, un diseño edificativo propio e inconfundible. Es entonces cuando surgen las primeras relaciones específicas entre dos tipos de profesionales, juristas y arquitectos, y el momento mismo en que comienzan a construirse los primeros Tribunales del Condado (Counties Courthouses) ${ }^{12}$.

Observando las imágenes de estas Courthouses creo que también resulta posible acercarse al entorno espacial y hasta a la atmósfera que rodeó a alguno de los dramas judiciales representados en el interior de aquellos edificios.

Y así, hayan estado o no más o menos cerca de la realidad histórica, o sólo apenas disimulados a través de la ficción literaria, percibiremos que tales edificios albergaron a mediados y finales del s. XVII juicios como los que una vez leímos novelados por Nathaniel Hawthorne en las páginas de

\footnotetext{
11 Un similar reparto del espacio se aprecia en los Swedish rural district courthouses, estudiados por Eva Löfgren (Göteborgs Universitet) en Rummet och rätten Tingshus som föreställning, byggnad och rum $i$ användning 1734-1970 (2011), y "This Is Not a Courthouse", en Kjell Å Modéer y Martin Sunnqvist (2012, p. 337-264). Löfgren precisa que en aquellos edificios llegaron a vivir niños, y que en los más antiguos se desarrollaban tareas domésticas como la cocción del pan y otros alimentos, habiéndose conservado algunos de los hornos que a tal efecto funcionaron.

${ }^{12}$ McNamara se ocupa igualmente de una etapa sucesiva, entre finales del s. XVIII y principios del XIX, donde junto a estos edificios van apareciendo otros también relacionados con la administración de justicia, como prisiones, oficinas de legalización de testamentos, y registros hasta conformar el todo conjunto de un complejo cerrado, separado del centro comercial de la ciudad, con zonas verdes y paseos.
} 
The scarlet letter (1850), o llevados a la escena en The Witches of Salen (1952), de Arthur Miller ${ }^{13}$.

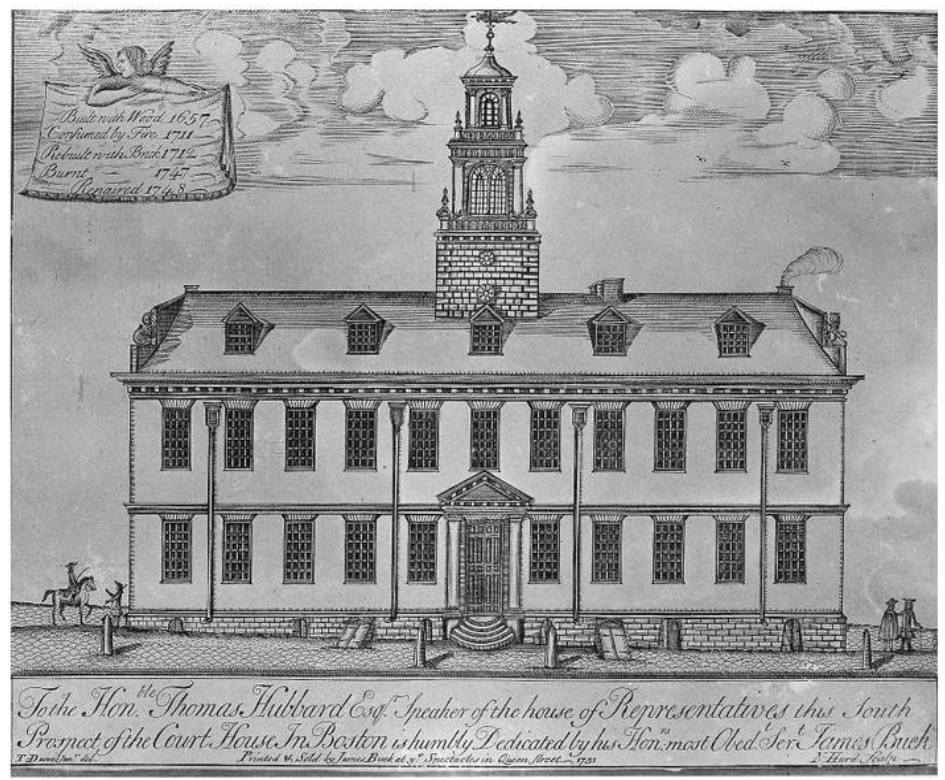

Court House Boston. Massachusetts, 1751, por Nathaniel Hurd

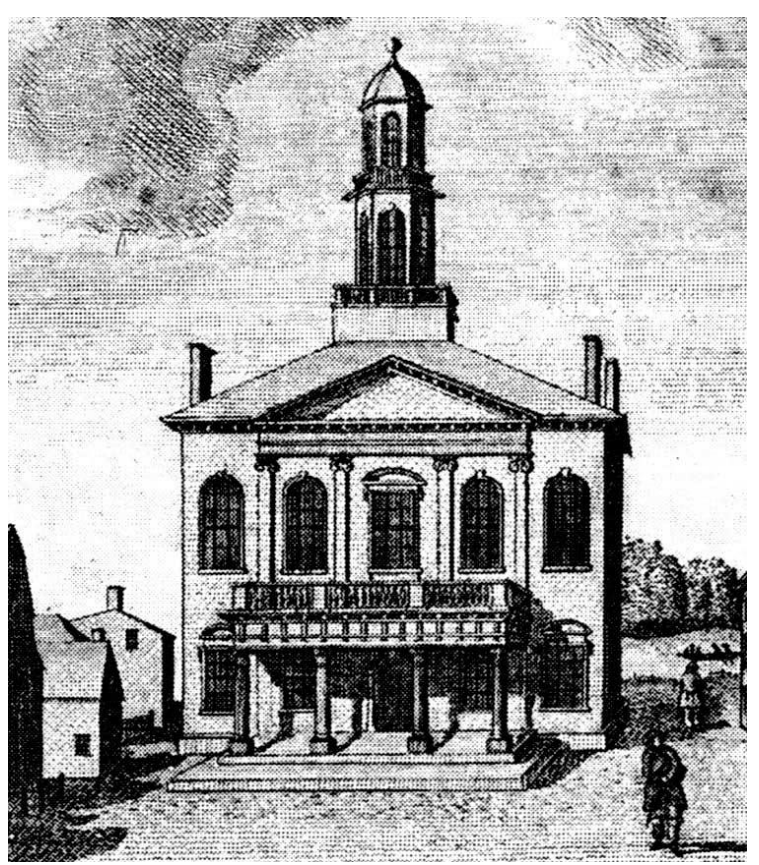

County Courthouse, Salem. Massachusetts. 1785

13 Vid. Nathaniel Hawthorne (1995) y Arthur Miller (1997). Asimismo, Claudia Durst Jonhson (2009) y Marta Mateo Martínez-Bartolomé (2000). 
En lo demás, creo asimismo que muy similar evolución y transformación experimentó el modelo constructivo en los inmuebles que abrigaron juzgados y tribunales en la mayoría de los condados y ciudades de Inglaterra.

Pero una referencia más quiero añadir aún. Es sobre Londres y hace a dos edificaciones que se conciernen, como son tribunales y cárceles, pero aquí y al caso en una lógica de dramatización arquitectónica tan singular como simbólica. Aludo al trabajo del arquitecto inglés George Dance II (1741-1825) en la elección del estilo y alzado de planos (1768-1769) para la construcción de la prisión de Newgate. La obra arquitectónica de George Dance II, que en viaje a Italia conoció y mantuvo trato de amistad con Battista Piranesi (1720-1778), quien había realizado los famosos aquaforti reunidos con el título de Carceri d'Invenzione (1761), es exponente de un neoclasicismo radical cuyo canon se agrava por el peso de la tradición medieval inglesa (Hyman, 1990, p. 520-521). La muestra quizá más evidente se encuentra en la fachada de la Newgate Prision, donde la energía ideológica del ius puniendi fisicaliza en materia, ofreciendo en toda su potencia el irracionalismo enérgico del lenguaje retributivo más exacerbado y duro.

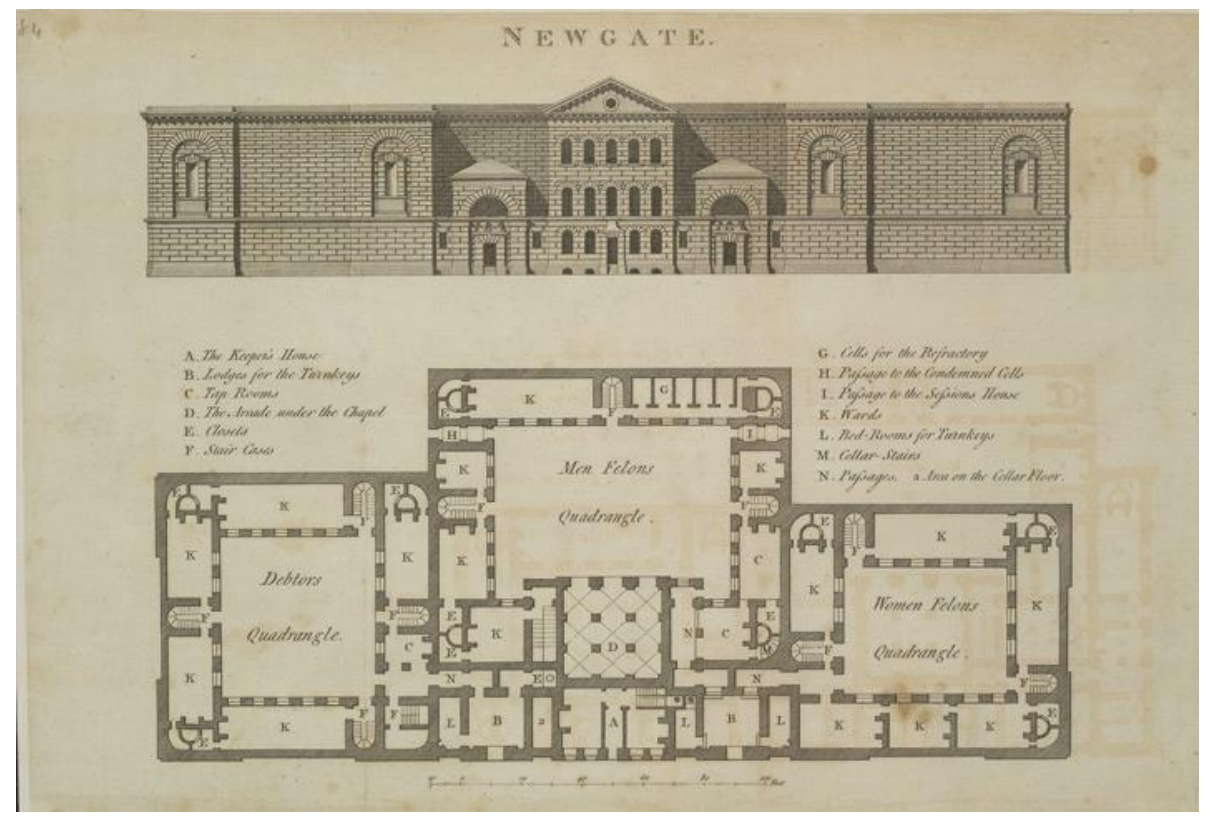

Newgate Prision, 1800 


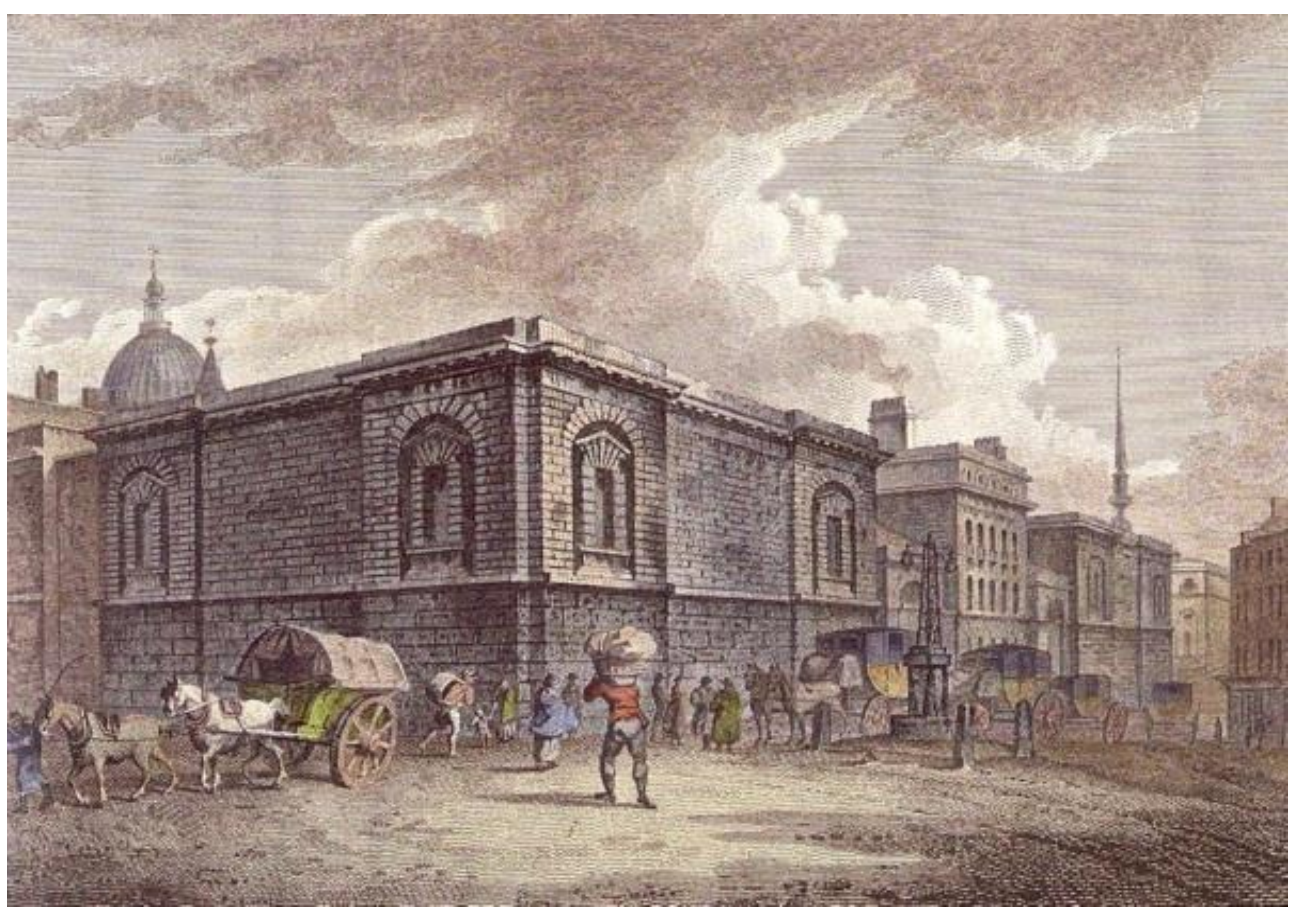

Vista Este de Newgate

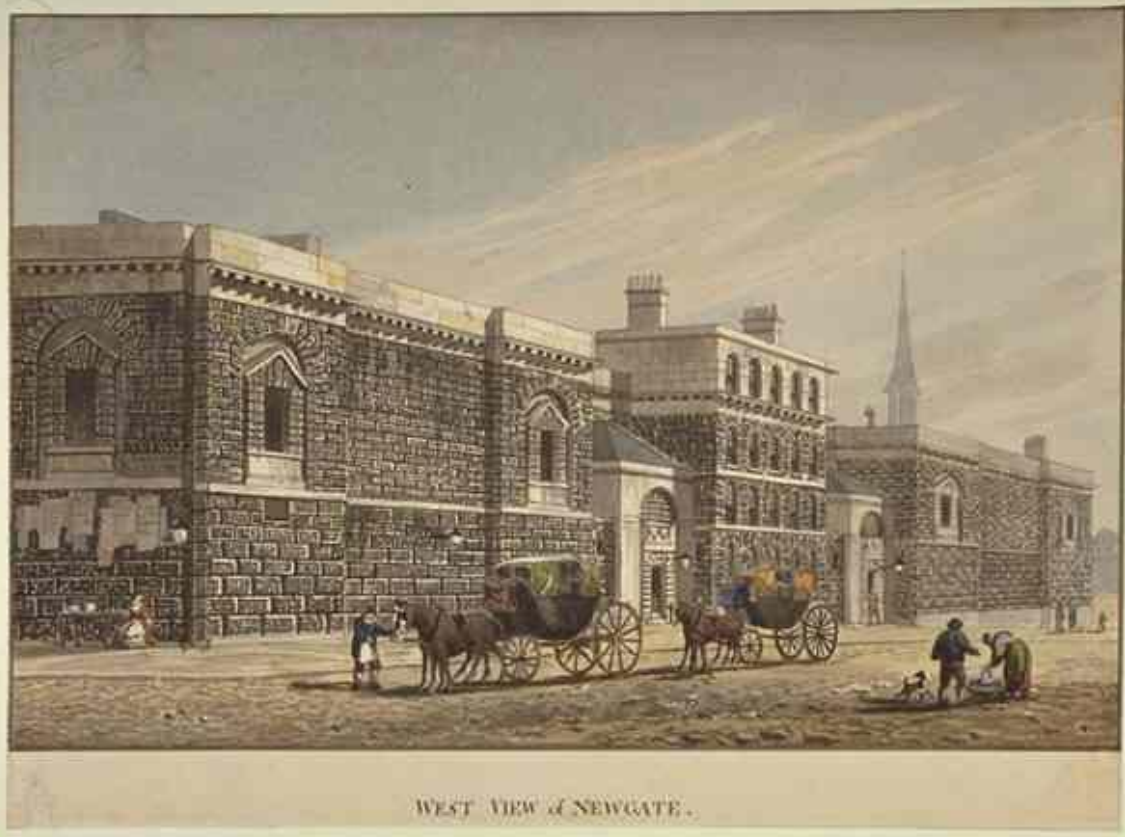

Vista Este de Newgate, por George Shepherd (1784-1862) 


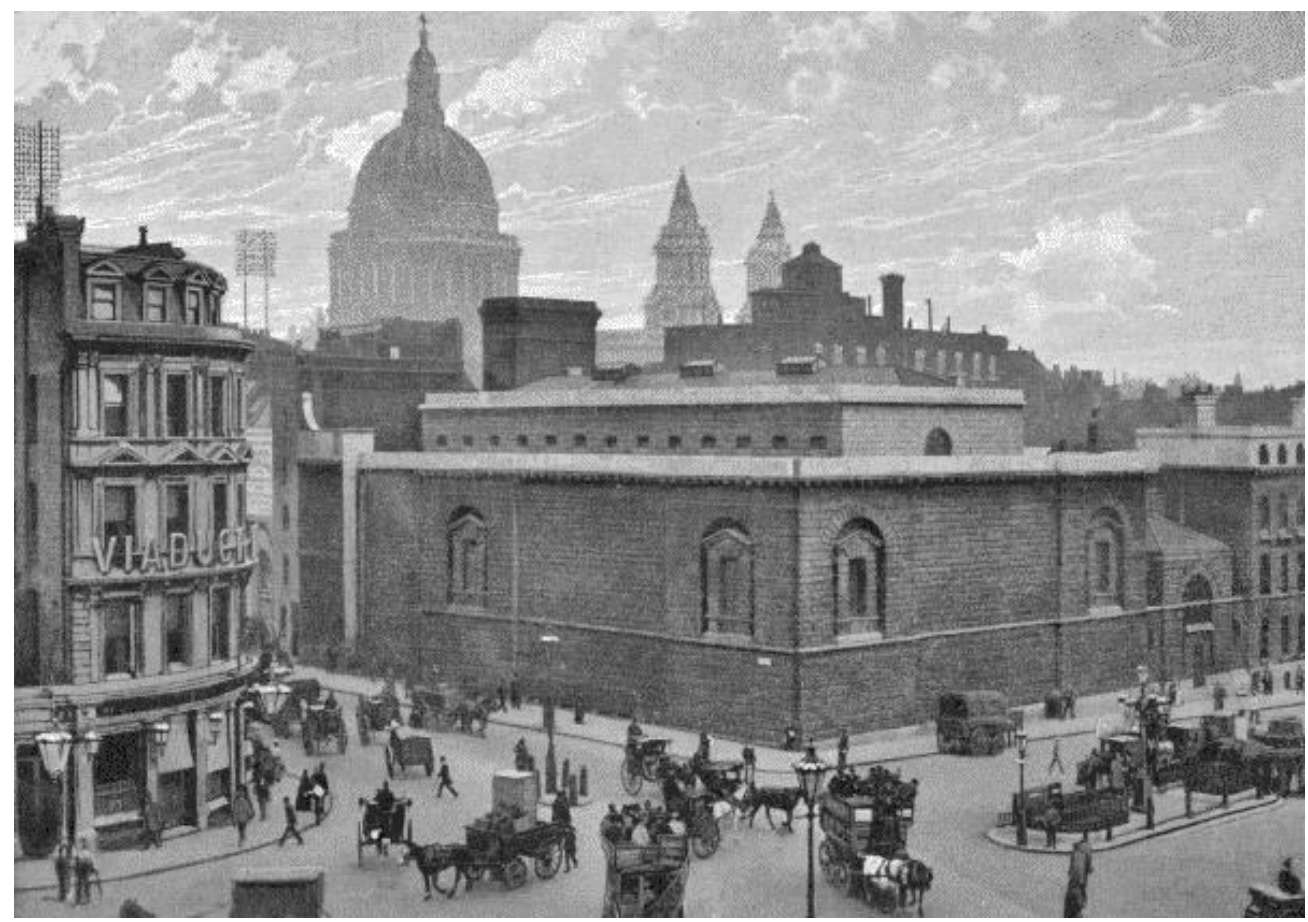

Newgate Prison y The Viaduct Tavern, 1897

El mensaje confinante escrito en la mampostería almohadillada de la fachada con ventanas ciegas es extraordinariamente expresivo de su terribilidad. De aquellos "gruesos muros ásperos" dijo Dickens que parecían hechos "for the express purpose of letting people in, and never letting them out again" ("con el propósito expreso de dejar entrar a la gente y no dejarla salir más")14. Y con dramática ironía describió su fábrica Huxley de este modo:

Behind the facade of Newgate $-a$ facade which its architect, uninhibited by the tiresome necessity of finding a place for windows, had been able to make consummately elegant- there existed, not a world of men and women, not even a world of animals, but a chaos, a pandemonium. ${ }^{15}$

14 Vid. Charles Dickens, Sketches by Boz: Illustrative of Every-day Life, and Every-day People, Chapter XXIV - 'Criminal Courts' (1837, p. 49). No es menos oportuna la lectura del siguiente cap., 'A visit to Newgate'. Por lo demás son multitud las menciones dickensianas a la cárcel de Newgate por ejemplo en Oliver Twist (1838), The Life and Adventures of Nicholas Nickleby (1838-1839) o Great Expectations (1861), y otras.

15 "Trás de la fachada de la londinense cárcel de Newgate - una fachada que su arquitecto, librado de la tediosa necesidad de abrir ventanas, pudo hacer excelsamente elegante-, existía, no un mundo de hombres y mujeres, ni un mundo de bestias, sin un caos, un pandemonium" (la cursiva es mina). Cf. Aldous Huxley (1960, p. 241). Este fragmento 


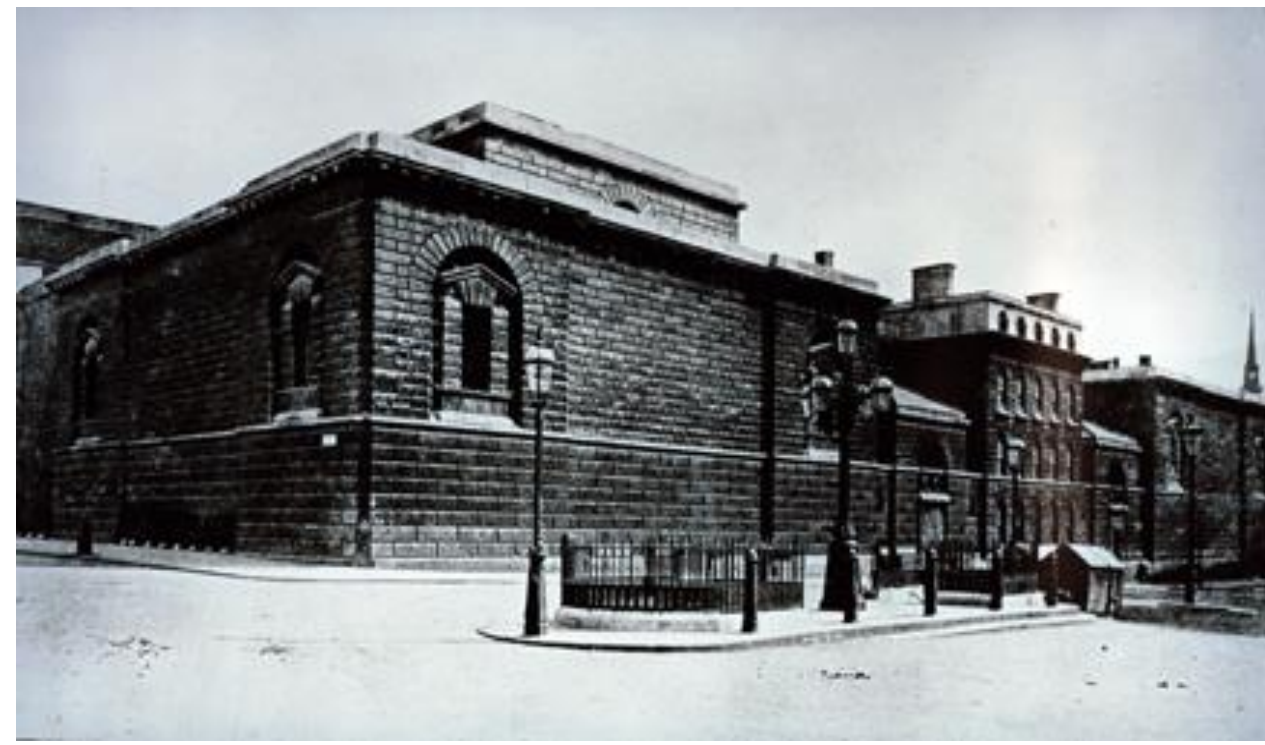

Pero no es menos inquietante el contraste con la disposición de los vanos en la Casa del Guardián. Mientras las ventanas de las celdas miran al interior del recinto, aquélla abría múltiples miradas al mundo atestando intensa y exhaustivamente su externidad.

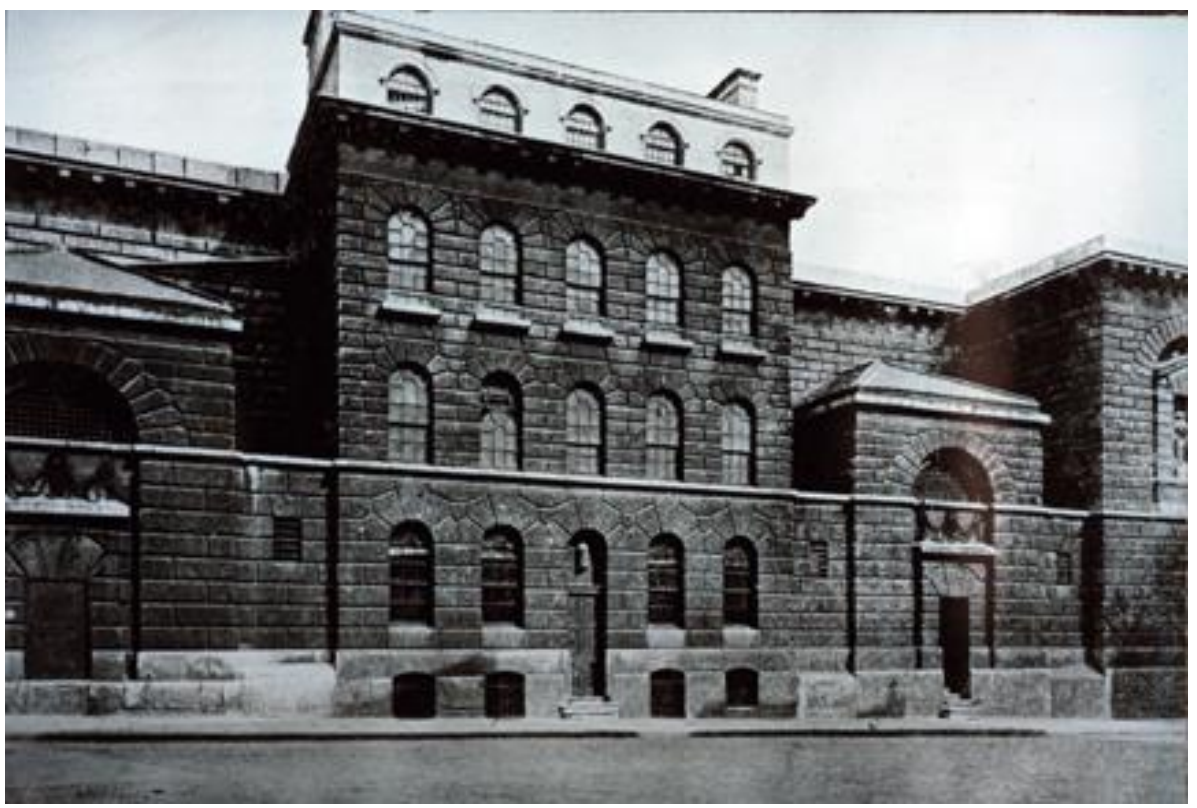

pertenece al texto que Huxley elaboró en 1940 para la edición de Carceri d'Invenzione (Trianon Press, London). En España se ha recogido con el título de "Cáceles" en la edición titulada Las cárceles de Piranesi, Casiniro Libros, Madrid, 2011, que igualmente incluye textos sobre el mismo tema a firma de Marguerite Yourcenar, Henri Focillon y Sergui Eisenstein. La cita en esta edición corresponde a la p. 25. No es menos provechosa la consulta de la edición e introducción a cargo de Hector O. Corfiato (1951). 
Los edificios de Old Newgate Prision, que venían ocupando el lugar donde ya desde el s. XII se ubicó una cárcel, fueron clausurados en 1902, iniciándose su demolición dos años más tarde. Old Newgate Prision llegó a ser la de mayor población reclusa entre las 150 existentes en Londres, con internos varones y mujeres no segregados y apenas clasificados. $\mathrm{Y}$ en su antiguo emplazamiento se decidió la construcción de The Central Criminal Court de Old Bailey, más conocido como Old Bailey Crown Court. Su inauguración oficial por el rey Enrique VII (1901-1910) se fechó a 27 de febrero de 1907.
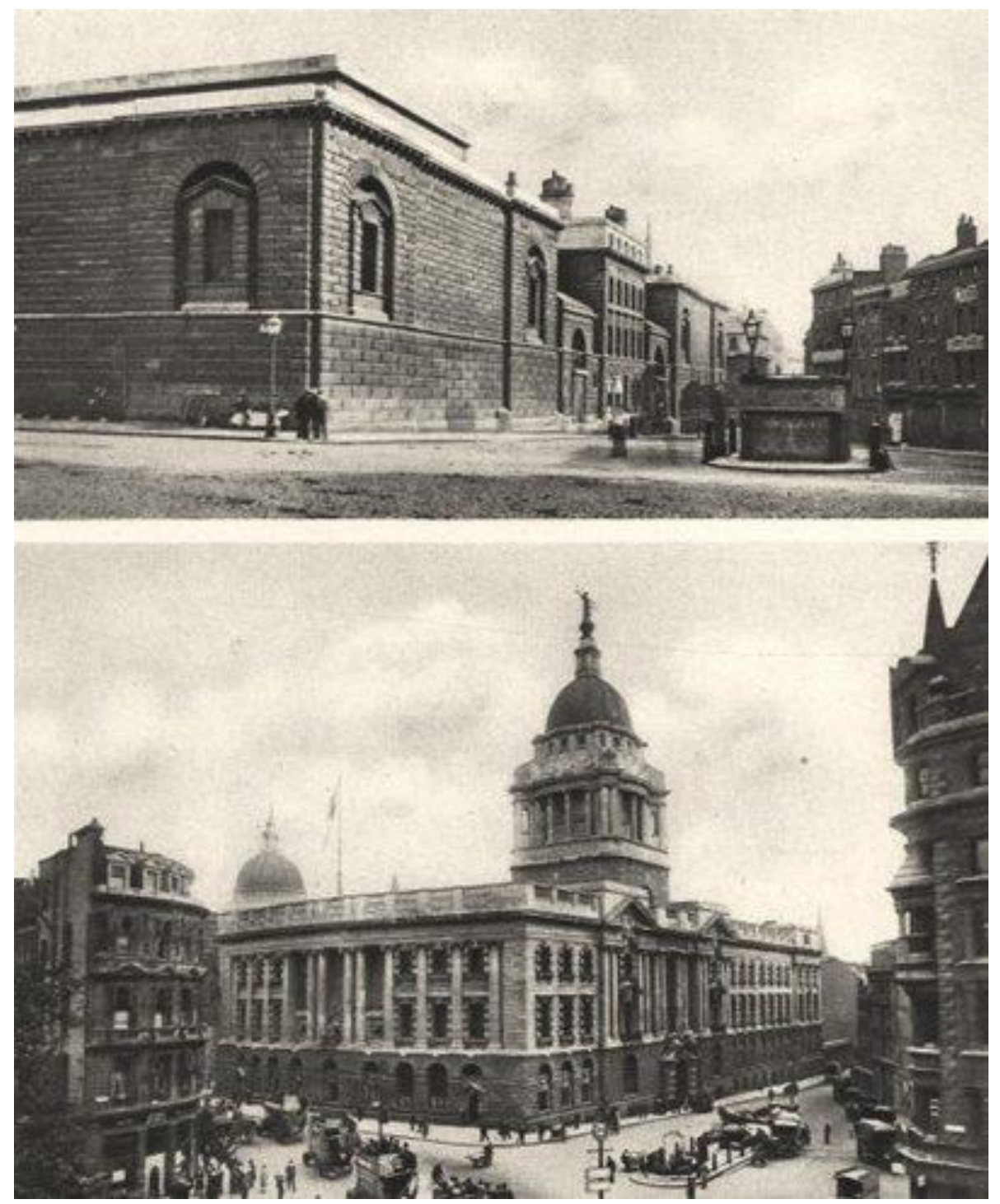

Arthur St John Adcock (ed.), Wonderful London: the world's greatest city described by its best writers and pictured by its finest photographers, Fleetway House, London, 1926-1927, v. II, p. 206 
El proyecto se había encargado al arquitecto Edward William Mountford (1855-1908), quien para el diseño exterior del nuevo inmueble eligió sujetarse al canon estilístico del momento, el llamado Edwardian Baroque (1841-1910), en realidad una variante neo-barroca que fusionaba con elementos de la tradición clásica.

La distinta misión a que el nuevo edifico iría destinado recomendaba, pues, utilizar una decoración menos austera y proporciones bien diferentes del anterior, más acordes ahora con la pompa y esplendidez de los Magistrats en majesté que en él juzgarían causas criminales; esto es, las relativas a conductas infractoras de valores positivos ético-sociales en el grado superior de su escala, y que por ello atañen a los principales bienes jurídicos de interés general, de donde también habían de ser objeto de especial protección por el Derecho penal (la existencia del Estado, la vida, la salud, la libertad, la propiedad, etc.).

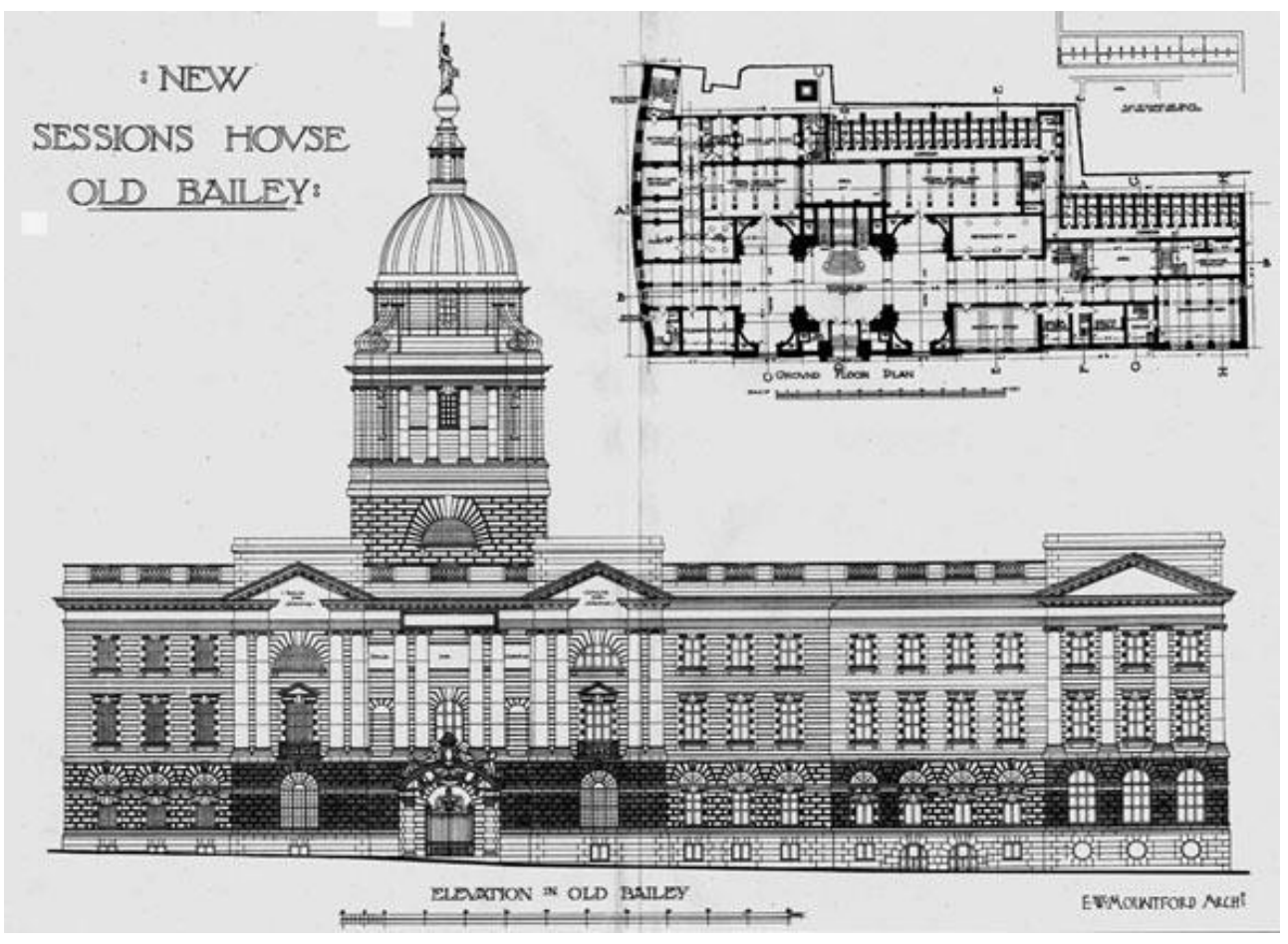

En consecuencia, la imagen del edificio debería ser robusta, pero por armonía a la solidez de su ambiciosa grandiosidad, y derrocharía abundante lujo y magnificencia en el gran estilo de su eclecticismo, de opulencia casi bizantina. Así, por tanto, haría olvidar para siempre la siniestra estampa de Newgate Prision. Un palacio vez de una mazmorra. 
No obstante, observando con atención su fábrica se advierte que la faja inferior, base sustentante de la elevación de todo el edificio, permanece en piedra sin labrar, como evocando el opus quadratum de aquellos viejos "gruesos muros ásperos" de que hablara Dickens. He aquí una metáfora estremecedora: que el apparatus de la Justicia calze, monte y grave sobre el recuerdo del Castigo; una Justicia con equivalencias en la función pragmática sólo ejemplarizante o aleccionadora de la pena.

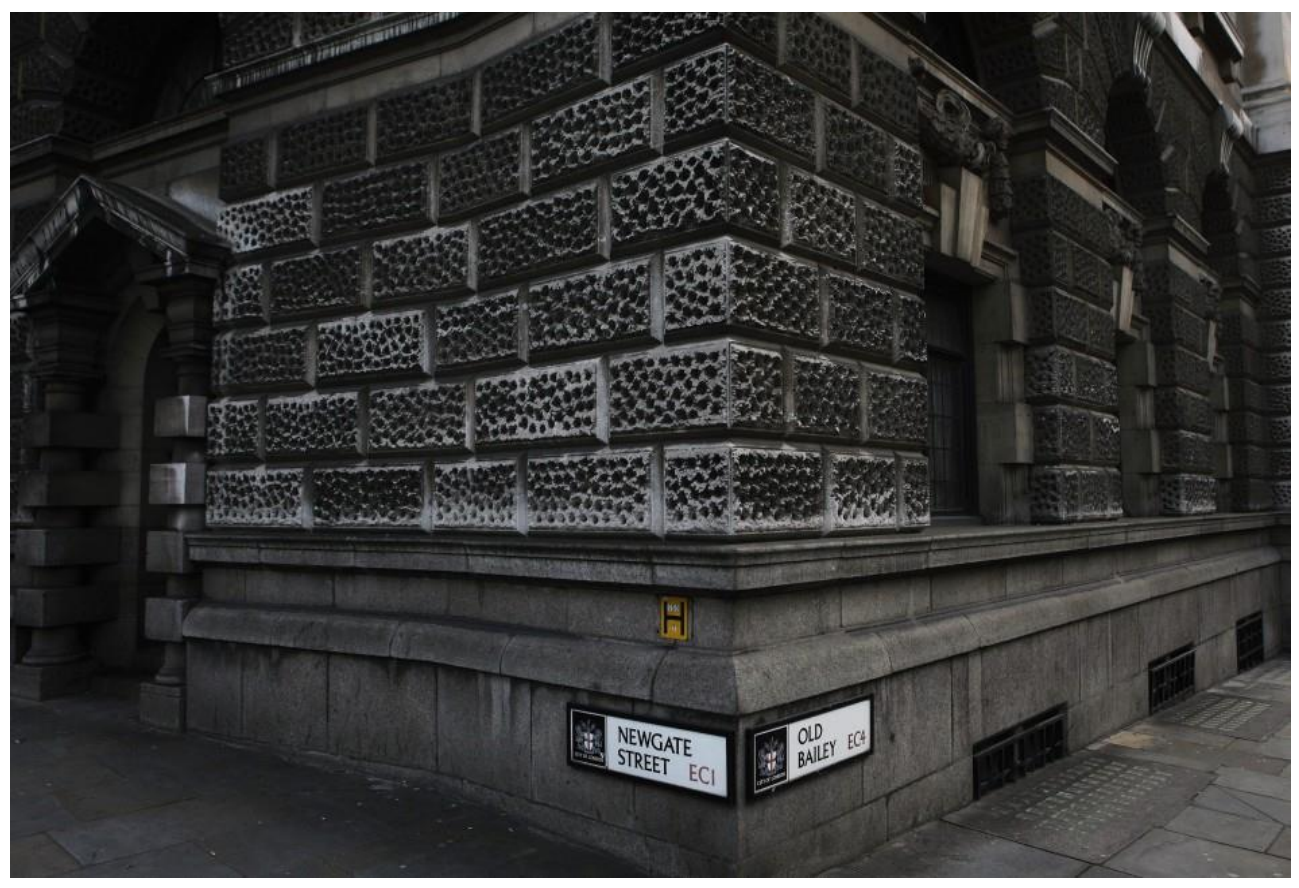

Y me pregunto si no sería acaso tanto más pavoroso que tal metáfora hiciera de asiento a toda Arquitectura jurídica, soportando y sosteniendo la entera validez del Derecho en el sillar disuasorio de la represión. ¿No se trataría entonces una obra toda infame y detestable?

\section{SOBRE DERECHO ARQUITECTÓNICO: LO ARQUITECTÓNICO EN LO JURÍDICO}

Más arriba me comprometí a ocuparme de posibles asuntos relacionados con las figuraciones arquitectónicas de que el Derecho aprovecha. Al tema, que muy bien podría dilatar en varias direcciones y desbaratarse, parece conveniente tallarle un armazón. En esa formatela o encofrado vierte como mortero la argamasa compuesta, sobre todo, de dos clases de componentes: histórico-políticos y lingüísticos. Aquél de fraguado 
lento y espeso, éste de ligazón muy dinámica y fluida. Lo que llamo Derecho arquitectónico resultaría de la aglomeración de ambos, de su trama sellada y compacta, pero interactiva. Mi propósito, sin embargo, se limita apenas a constituir una primera retícula base, de apoyo, facilitando algunas muestras de su cuaja. Así, la trabazón Derecho \& Arquitectura admite explorar ámbitos como los siguientes:

\section{A) Poder estatal y Arquitectura del castigo}

Desde que el Estado moderno se reserva al lado del monopolio normativo y el de la coacción física legítima (ofensiva o defensiva) ${ }^{16}$, puede decirse que su constitucionalidad orgánica se encuentra ligada al Derecho penal; es decir, que su Derecho constitucional es el Derecho penal. Entonces, sólo la arquitectura del castigo puede ser también su arquitectura más característica.

Conocidos son los trabajos precursores de Foucault (1975). Su inquietud intelectual ha tenido especial seguimiento en el mundo anglosajón, donde ahora las investigaciones se centran cada vez más en los diseños arquitectónicos de las prisiones (radiales, lineales y centrales con cédulas satélite, como en la actualidad), llevando a cabo un escrutinio específico -más allá de enjundiosos estudios históricos ${ }^{17}-$ de los modelos que con mayor frecuencia se edifican, su modificación conforme a la aceptación o rechazo -en especial durante el s. XX- de unas u otras filosofías penales o políticas criminales, y su internacionalización, o la comparativa con los sistemas de seguridad y control de la arquitectura "normal"18. Las diferentes arquitecturas del castigo reflejan los modelos de Estado, y de sociedad, a las que sirven. El estudio del espacio penitenciario

\footnotetext{
16 "Si el uso de la fuerza es la condición necesaria del poder político, sólo el uso exclusivo de este poder es la condición suficiente”. Cf. Bobbio (1999, p. 108). Por su parte Friedrich A. Hayek, citando entre otros a Ihering, Weber y Malinowsky, escribe: "La coacción no puede evitarse totalmente, porque el único camino para impedirla es la amenaza de coacción. La sociedad libre se ha enfrentado con este problema confiriendo al estado el monopolio de la coacción, intentando limitar el poder estatal a los casos que sea necesario ejercerlo [...] la coacción que el poder público debe utilizar para dicho fin se reduce al mínimo y resulta tan inocua como sea posible mediante la subordinación a normas generales conocidas" (2011, p. 71-72).

17 Vid. Robin Evans (2011). En España, el sobresaliente trabajo de Pedro Fraile (1987). En Iberoamérica, Valeria Sánchez Michel (2008).

${ }^{18}$ Vid. Leslie Fairweather e Sean McConville (2003), Johnston Norman (2007).
} 
recibe asimismo importante nutriente desde el aporte del Law \& Humanities (Derecho y Literatura, Derecho y Artes gráficas) y sus análisis críticos ${ }^{19}$.

\section{B) Poder judicial y Arquitectura constitucional}

Los tribunales constitucionales se incluyen comúnmente entre las llamadas instituciones fundamentales del sistema jurídico-político en que descansa el edificio constitucional. En un estudio de difusión apenas estrenada, Justin Crowe (2012), Profesor asociado de Ciencia Política en el Williams Collage de Williamstown, Massachussets, ofrece sugestivo examen acerca de la relevancia arquitectural que dentro del modelo de democracia constitucional estadounidense -sea la versión jeffersoniana o la jacksoniana- posee el poder judicial federal (Supreme Court). Es un recorrido que principia en 1789 y se prolonga hasta finales del s. XX indagando en su autonomía, independencia y autoridad fundacionales, en la consolidación de sus funciones jurisdiccionales y en las intervenciones que, para su transformación y/o reforma, han sido pretendidas y/o alcanzadas desde el ámbito político partidista y/o empresarial.

\section{C) Proceso judicial y Arquitectura de interior}

Acudo a Linda Mulcahy (2011) ${ }^{20}$, Profesora de Derecho en la London School of Economics, quien en un trabajo de fecha todavía reciente aborda de qué modo la disposición arquitectónica de las salas de juicios y el acomodo en ellas del diverso mobiliario judicial (interiorismo) pueden ser interpretados como reflejo de una tensión histórico-jurídica y política que ha ido produciendo la asignación de determinados roles de conducta procesal, y en donde abrir espacios relacionados con las garantías judiciales del debido proceso legal (due process of law; garantía de legalidad, de imparcialidad, juez natural, limitación plenamente justificada de derechos fundamentales, etc.) e inviolabilidad de la defensa, y dar lugar a principios informadores del proceso como los de audiencia, contradicción o igualdad

19 Vid. John Bender (1989), con análisis de Robinson Crusoe o The Fortunes and Misfortunes of the Famous Moll Flanders, de Daniel Defoe, The Beggar's Opera, de Jonh Gay, y las ilustraciones y grabados de Willians Hogarth (The Harlot's Progresses) para The History of the Life of the Late Mr Jonathan Wild the Great, y Amelia de Henry Fielding.

20 También de la misma autora algún adelanto en su trabajo "Architects of Justice: the Politics of Courtroom Design” (2007). 
de armas, sobre todo respecto de la proposición y práctica de la prueba. La evolutiva organización, distribución y demarcación de distintas zonas espaciales del juicio -que no siempre ha sido ni fácil ni sencilla- o de la diferente limitación de acceso y movimientos dentro de ellas -que tampoco lo fue- resulta demostrativa de ciertas realidades no ingenuas para con la ideología jurídico-política del sistema judicial y su funcionamiento. La autora, por ejemplo, señala cambios en la aparente neutralidad del espacio derivados en esa arquitectura de interior de la mayor área actualmente concedida a las defensas, de la decreciente superficie asignada al público, y también de los efectos de desmaterialización del espacio en las dinámicas de confrontación probatoria consecuencia de la irrupción - generalmente positiva, pero a veces también amenazadora - de las nuevas tecnologías en el proceso, y por tanto de una arquitectura virtual y sus des-ubicaciones.

\section{D) Teoría jurídica y Artificio.}

En el pensamiento jurídico moderno la Teoría del Derecho renuncia a falacias naturalistas. Desde Hobbes, y en especial Hume ${ }^{21}$, la idea de Artificio es inmanente al Derecho. Quizá desde antes, cum meritus, por el sabiniano Celso en D. 1, 1,1: Ius est ars boni et aequi; id est, el derecho el 'artificioso'. La contemporaneidad jurídica -aprovechando de la distinción bergsoniana entre l'immédiat et le médiat, l'acte et l'œuvre (Bergson, 1889) - lo subrayará con Geny: «L'activité du jurisconsulte (au sens le plus élevé du mot) oscille entre deux pôles distincts que je proposerai de dénommer le donné et le construit» (1922, p. 97)22. Insistirán sobre esta polaridad Léon Duguit (2008)23, también Georges Ripert (1949) y otros, como Alfredo Colmo $(1927 ; 1928)$.

Por mi parte, expresando afinidad a este modernismo jurídico, postulo una teoría narrativa del Derecho (Calvo Gonzales, 2008) donde more classico:

\footnotetext{
${ }^{21}$ Vid. Gianluigi Palombella (1984). También del mismo autor Filosofia del Diritto, Parte prima, Cap. I - 'Diritto natuale, rgione, artificio' (1996, p. 13-31). En español, ver. José Calvo González, Filosofía del Derecho moderna y contemporánea, (1999, p. 15-28).

22 También de la misma obra en ed. de 1927 (en tres v.), v. II pp. 371-389 (donnés), y v. II 520-522 (donné et construit). La dicotomía se gesta ya en Méthode d'interprétation et sources en droit privé positif: essai critique (1899).

23 En espc. première conférence de Madrid (2008, p. 157-158) y conférence de Lisbonne du 28 novembre 1923 (2008, p. 201-202).
} 
a) Ius est ars inventio disponiendi

b) Lex est ius a peritis principibus constitutum

\section{y E) Teoría de la Argumentación jurídica y símiles arquitectónicos}

La presencia en Derecho de analogías, símiles, metáforas y tropos es abundante y frecuentísima, y su estudio se ha intensificado en los últimos años ${ }^{24}$. Se trata en todos los casos de figuras retóricas esenciales, aunque no siempre tan equivalentes, como por lo común se cree. A menudo pasan por metáforas lo que en realidad son símiles, y no faltan inadvertidos que consideran analogías lo que son ficciones.

La comparativa arquitectónica quizá más famosa de toda la cultura jurídica pertenece sin duda a Aristóteles. Se encuentra en pasajes de su Retórica y de la Ética a Nicómaco ${ }^{25}$ donde el Estagirita expone la noción de

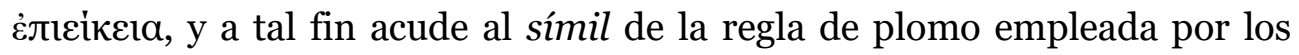
arquitectos de Lesbos en la edificación de los muros de piedra; comoquiera que no todas las piedras disponibles son iguales, la regla que las mide debe adaptarse a la superficie de las piedras, y no tanto éstas a la regla. "Cuando la cosa está indeterminada e indefinida, entonces la norma debe estar también indeterminada, de modo similar a la regla de plomo usada para hacer el molde lésbico: la regla se adapta a la figura de la piedra y no es rígida; así, de modo similar, el fallo se adapta a los hechos”. La búsqueda de una decisión justa como equitativa (equity, fairness, reasonableness) exige proceder con criterios flexibles, adaptativos. Ante la rigidez legal el juzgador debe mostrar -si se me permite expresarlo así- aptitudes "ergonómicas".

A esa fama del símil aristotélico no le aventaja ni aún la metáfora hídrica o hidrológica de las "fuentes del Derecho" como formas de manifestación del Derecho ${ }^{26}$, y queda también muy lejos de ella el tropo arborescente -antes barroco, o neobarroco ${ }^{27}$, que racionalista, a mi juicio-

24 Vid. Gérard Timsit, «La métaphore dans le discours juridique» (2000, p. 83-97) y "L'ordre juridique comme métaphore» (2001, p. 3-18); Michel Stolleis (2004); Francesco Galgano (2010); Claudio Sarra (2010); Finn Makela (2011, p. 397-415).

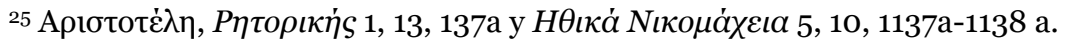

${ }^{26}$ Cicerón, De inv. 2, 65-68; De legibus 1, 16-19, De partitione oratoria 37, 129-131, o Topica $5,28$.

27 Así Joseph Raz (1980, p. 99), por entender que la estructira pyramidal propuesta por Adolf Merkl y Han Kelsen induce al grave error - "indeseable error", escribe - de creer que 
empleado para explicar a través de raíces y ramas las nociones de sistemática, jerarquía, desarrollo y crecimiento normativo (Premont, 2003).

Pero la retórica aristotélica no agotó el recurso al símil arquitectónico. La nouvelle rhétorique perelmiana (Perelman; Olbrechts-Tyteca, 1958), transpuesta en el interés de los juristas como Teoría de la Argumentación jurídica $^{28}$, ha renovado la utilización de elementos y parámetros arquitectónicos en la presentación y elaboración de enunciados y proposiciones, de tesis y definiciones. Y es que la lógica proposicional en el proceso argumentativo se concibe, de principio a fin, como una ‘construcción'. Es de esa manera que la retórica figurativa y los tópicos léxicos conectan con la Arquitectura.

En efecto, el argumento ha de estar construido con proposiciones lógicas a las que se requiere consistencia; o expresado de otro modo: se dice que un argumento es consistente cuando está bien construido y sirve para sustentar la tesis.

Y también, la tesis se sustenta en argumentos sólidos, o argumentos de peso (buenas razones, good reasons). La tesis contraria, o antítesis, tratará de quitar peso o aligerar los argumentos de adverso. En un argumento de poco peso (argumento débil, lightweight argument) no es posible sustentar la tesis, o la antítesis, pues esa debilidad lógica arriesga salvo refuerzo- desequilibrar la estructura constructiva del edificio argumental en su conjunto, precipitando un proceso de fracaso y colapso que lo derrumbe estrepitosamente, como si se tratara de un castillo de naipes.

Personalmente prefiero estos símiles arquitectónicos a otros que en la argumentación jurídica se han utilizado. No me desagradan los aprovechados de la Física (onus probandi, carga de la prueba) o la Dinámica (doctrina de las cargas dinámicas probatorias), y desde luego son preferibles a otros que, para rehusar, refutar o impugnar argumentos basados en inferencias falibles o normas condicionales glosan la

en el sistema jurídico existe siempre un igual número de niveles normativos que el mostrado en la Normpyramide de aquéllos.

${ }^{28}$ Vid. Guillaume Vannier, Argumentation et Droit: une introduction à la nouvelle rhétorique de Perelman (2001). 
terminología bélica; v. gr., derrotable, derrotabilidad (defeasible conditionals).

Pero seguramente es éste un asunto de modas lingüísticas. Y es posible que yo esté demodé, porque en teoría de la argumentación jurídica prefiero al homo arquitectonicus antes que al homo bellicus.

El origen de esa preferibilidad es axiológica. Del vínculo Derecho y Arquitectura en la dimensión de un imaginable Derecho arquitectónico, y particularmente en lo relacionado con Argumentación jurídica, continua atrayéndome el valor de unas palabras leídas al comienzo de Los diez libros de Arquitectura de Vitruvio (1995). Dicen:

\begin{abstract}
$\mathrm{y}$, de esta forma, cultivando su ingenio en las posibles disputas o debates, lograron construir cada día con más gusto y sensatez. ${ }^{29}$
\end{abstract}

\title{
REFERENCIAS
}

BENDER, John. Imagining the Penitentiary: Fiction and the Architecture of Mind in Eighteenth-Century England. Chicago: University Of Chicago Press, 1989.

BERGSON, Henri. Essai sur les données immédiates de la conscience Paris: F. Alcan, 1889.

BOBBIO, Norberto. Estado y sociedad, por una teoría general de la política. 7. reimpr. México: FCE, 1999.

CALVO GONZÁlEZ, José. Fỉlosofía del Derecho moderna $y$ contemporánea. 2. ed. Madrid: Tecnos, 2002.

CALVO GONZALEZ, José. Octroi de sens. Exercices d'interpretation juridique-narratif. Québec: Les Presses de l'Université Laval, 2008.

COLMO, Alfredo. De las obligaciones en general: tratado teórico-práctico de las obligaciones en el derecho civil argentino. 2. ed. corr., aum. y puesta al día. Buenos Aires: J. Mene' ndez, 1928.

COLMO, Alfredo. Técnica legislativa del código civil argentino. 2. ed. Buenos Aires: Bartolomé Mitre de Hall y Acevedo, 1927.

CORFIATO, Hector O. Piranesi Compositions. London: Alec Tiranti, 1951.

CROWE, Justin. Building the Judiciary: Law, Courts, and the Politics of Institutional Development. Princenton (NJ): Princeton University Press, 2012.

\footnotetext{
29 Vid. Vitruvio [Marcus Vitruvius Pollio], Los diez libros de arquitectura, Lib. I, Cap. 1 - 'Las comunidades primitivas y el origen de los edificios' y Delfín Rodríguez Ruiz, "Vitruvio y la piel del clasicismo" (1995, p. 11-51).
} 
DICKENS, Charles [\& William Henry Wills]. A Coroner's Inquest, Household words: A Weekly Journal, 1, 27 april 1850], p. 109-113.

DICKENS, Charles. Sketches by Boz: Illustrative of Every-day Life, and Every-day People. London: John Macrome, 1837.

DUGUIT, Léon. Le pragmatisme juridique: conférences prononcées à Madrid, Lisbonne \& Cö̈mbre, 1923. Prés. et trad. par Simon Gilbert. Paris: La Mémoire du Droit, 2008.

EVANS, Robin. The Fabrication of Virtue: English Prison Architecture, 1750-1840. 2. ed. Cambridge University Press, 2011.

FAIRWEATHER, Leslie; McCONVILLE, Sean (eds). Prison architecture: policy, design and experience. Oxford: Architectural Press, 2003.

FOUCAULT, Michel. Surveiller et punir: Naissance de la Prison. Paris: Gallimard, 1975 .

FRAILE, Pedro. Un espacio para castigar. La cárcel y la ciencia Penitenciaria en España (Siglos XVIII-XIX). Barcelona: Ediciones del Serbal, 1987.

GALGANO, Francesco. Le insidie del linguaggio giuridico. Saggio sulle metafore nel diritto. Bologna: Il Mulino, 2010.

GENY, François. Méthode d'interprétation et sources en droit privé positif: essai critique. Précédé d'une préface de M. Raymond Saleilles, Paris : A. Chevalier-Marescq, 1899.

GENY, François. Science et technique en droit privé positif. Nouvelle contribution à la critique de la méthode juridique. Paris: Sirey, 1922. v. I.

GENY, François. Science et technique en droit privé positif. Nouvelle contribution à la critique de la méthode juridique. Paris: Sirey, 1927. 3v.

HAWTHORNE, Nathaniel. La letra escarlata. Trad. de Pilar y José Donoso. Barcelona: Plaza \& Janés, 1995.

HAYEK, Friedrich A. The Constitution of Liberty: The Definitive Edition. Chicago: Ronald Haamony ed.; University of Chicago Press, 2011.

HUXLEY, Aldous. Las cárceles de Piranesi Madrid: Casiniro, 2011.

HUXLEY, Aldous. On art and artists. New York: Meridian Books, 1960.

HYMAN, Marvin Trachtenberg-Isabelle. Arquitectura. Trad. de Alicia González Sterling. Madrid: Akal, 1990.

JONHSON, Claudia Durst (ed.). Justice in Arthur Miller's the Crucible (Social Issues in Literature). San Diego (CA): Greenhaven Press, 2009.

KONDRATIEFT, Erik . The Urban Praetor's Tribunal in Roman Republic. In: DE ANGELIS, Francesco (ed.). Spaces of Justice in the Roman World. Leiden; Boston: Brill Academic Publishers, 2010. p. 87-126.

LÖFGREN, Eva. Rummet och rätten Tingshus som föreställning, byggnad och rum i användning 1734-1970 [Space and court: Swedish rural district courthouses as conception, buildings and space in practice 1734-1970]. Stockholm:, Institutet för rättshistorisk forskning, 2011. 
LÖFGREN, Eva. This Is Not a Courthouse. In: MODÉER, Kjell A; SUNNQVIST, Martin. Legal Stagings: The Visualization, Medialization and Ritualization of Law in Language, Literature, Media, Art and Architecture. Copenhagen: Museum Tusculanum Press, 2012. p. 337-264.

MAKELA, Finn. Metaphors and Models in Legal Theory, Les Cahiers de Droit (Université Laval, Québec, 52, 3-4, p. 397-415, Septembre-Décembra, 2011.

MALAVÉ OSUNA, Belén. Legislación urbanística en la Roma imperial. A propósito de una constitución de Zenón. Málaga: Servicio de Publicaciones e Intercambio Científico de la Universidad Málaga, 2000.

MARTÍNEZ-BARTOLOMÉ, Marta Mateo. «Las brujas de Salem» y «El crisol»: las versiones españolas de la obra de A. Miller en teatro, tv y cine (documentos), Quaderns: Revista de traducció, 5, p. 147-160, 2000.

MAZZACANE, Aldo. El jurista y la memoria. In: PETIT, Carlos (ed.). Pasiones del jurista: amor, memoria, melancolía, imaginación. Textos de António M. Hespanha, Aldo Mazzacane, Pierangelo Schiera, Pietro Costa. Trad. de Esteban Conde. Madrid: Centro de Estudios constitucionales, 1997. p. 75-114.

McNAMARA, Martha J. From Tavern to Courthouse: Architecture and Ritual, American Law 1658-1860, Baltimore: Johns Hopkins University Press, 2004.

MILLER, Arthur. Las brujas de Salem. El Crisol. Trad. de José Luis López Muñoz. Barcelona: Tusqets Editores, 1997.

MULCAHY, Linda. Architects of Justice: the Politics of Courtroom Design, Social \& Legal Studies, 16, 3, p. 383-403, 2007.

MULCAHY, Linda. Legal Architecture: Justice, due process and the place of Law. New York: Routledge, 2011.

NORMAN, Johnston. Forms of Constraint. A history of prison architecture. 2. ed. Champaign: University of Illinois Press, 2007.

PALOMBELlA, Gianluigi. Diritto e artificio in David Hume. Milano: Giuffrè, 1984.

PALOMBELLA, Gianluigi. Diritto natuale, rgione, artificio. In: Filosofia del Diritto. Padova: Cedam, Padova, 1996. p. 13-31.

PERELMAN, Chaïm; OLBRECHTS-TYTECA, Lucia. Traité de l'argumentation - La nouvelle rhétorique. Paris: PUF, 1958.

PREMONT, Marie-Claude. Tropismes du droit. Logique métaphorique et logique métonymique du langage juridique. Montréal: Liber, 2003.

RAZ, Joseph. The concept of a legal system. 2. ed. New York: Oxford University Press, 1980.

RIPERT, Georges. La règle morale dans les obligations civiles. Paris: LGDJ, 1949.

RODRÍGUEZ RUIZ, Delfín. Vitruvio y la piel del clasicismo. In: VITRUVIO [Marcus Vitruvius Pollio]. Los diez libros de Arquitectura. Madrid: Alianza, 1995. p. 11-51. 
SÁNCHEZ MICHEL, Valeria. Usos y funcionamiento de la carcel novohispana. El caso de la Real Cárcel de Corte a finales del siglo XVIII. México: Colegio de México, 2008.

SARRA, Claudio. Lo scudo di Dioniso. Contributo alla studio della metafora giuridica. Principi di filosofia forense. Milano: Franco Angeli Edizioni, 2010.

STOLLEIS, Michel. Das Augen Des Gesetzes: Geschichte Einer Metapher. München: C.H. Beck Verlag, 2004.

TIMSIT, Gérard. La métaphore dans le discours juridique, Revue européenne des sciences sociales, 38, p. 83-97, 2000.

TIMSIT, Gérard. L'ordre juridique comme métaphore, Droits, 33, p. 3-18, Oct. 2001.

VANNIER, Guillaume. Argumentation et Droit: une introduction à la nouvelle rhétorique de Perelman. Paris: PUF, 2001.

VITRUVIO [Marcus Vitruvius Pollio]. Los diez libros de Arquitectura. Trad. de José Luis Oliver Domingo. Madrid: Alianza, 1995.

Lengua original: Español

Recibido: 11/02/2015

Aceptado: 21/04/2015 